\title{
Soil Mechanics Surface Sampler
}

\begin{abstract}
R. F. SCOTT ${ }^{1}$ AND F. I. RoBERSON ${ }^{2}$
A lunar surface sampler essentially identical to that operated from Surveyor 3 was mounted on Surveyor 7 and performed flawlessly on the moon throughout a range of operating temperatures from $+180^{\circ} \mathrm{F}$ to $-167^{\circ} \mathrm{F}$. The motor current was sampled during lunar bearing and trenching tests, and these data, together with preflight calibrations enabled us to calculate the forces involved in these tests. After minimal lunar surface testing, the surface sampler was employed to release the sensor head of the $\alpha$-scattering instrument, which had jammed in its background position. Subsequently, the sensor head was relocated to analyze a rock and, still later, to analyze some subsurface lunar material. The mechanical tests of the surface in the vicinity of Tycho indicated that the surface behaved in a manner that was quantitatively similar to the behavior of the material close to Surveyor 3 , but the surface near Tycho appeared qualitatively to be more deformable and less brittle. A rock was weighed and found to have a density between 2.4 and $3.1 \mathrm{~g} / \mathrm{cm}^{\mathrm{s}}$ (earth basis). Another rock was broken by a moderately hard blow from the sampler. The soil varied in depth from 1 to at least several inches over underlying rock fragments near Surveyor 7. Little adhesion of lunar soil to the mirror surface of the $\alpha$-scattering experiment sensor head was observed over a 24-hour period.
\end{abstract}

\section{SUBSystem DescRIPTION}

The physical design of the surface-sampler mechanism and its auxiliary electronics unit is the same as that of Surveyor 3 [Scott and Roberson, 1967]. The subsystem, as discussed here, includes the mechanism, its auxiliary, wiring harness, and mounting substructure.

Mechanism, motors, and electronics. The extension/retraction mechanism, the motors, and auxiliary electronics unit are described by $S$ cott and Roberson [1967] and Rouze et al. [1968]; the primary change made on Surveyor 7 consisted of an increase in the capacity of the electronic auxiliary heater to 7.5 watts.

Scoop. The surface-sampler scoop is attached to the end of the extension/retraction mechanism (Figure 1). On Surveyor 7, the flat foot of the scoop door incorporated two embedded rectangular horseshoe magnets. In Figure 2 these magnets are shown outlined by fine-grained material after they made contact with the lunar surface.

Temperature sensors. In addition to the temperature sensor within the auxiliary electronics

\footnotetext{
${ }^{1}$ California Institute of Technology, Pasadena, California 91109.

2 Jet Propulsion Laboratory, California Institute of Technology, Pasadena, California 91103.
}

Copyright @ 1969 by the American Geophysical Union. unit, the elevation and retraction motors have a sensor attached to each motor housing (Figure 1).

Mounting substructure. The surface sampler is mounted below the survey television camera and to the right of the $\alpha$-scattering instrument, as viewed from the position of the television camera. The relative positions of the surface sampler, television camera, and $\alpha$-scattering instrument between footpads 2 and 3 of the Surveyor 7 spacecraft are shown in Figure 1 of Choate et al. in this report (page 6150). The mounting substructure was designed to provide the surface sampler with the capability of reaching the sensor head of the $\alpha$-scattering instrument in its normally deployed position on the lunar surface and redeploying it to another selected location. The design of the azimuth drive prevents the surface sampler from reaching footpad 2. The areas of surface-sampler operations and $\alpha$-scattering instrument redeployment capability are shown in Figure 3.

\section{Functional and Operational Description}

The surface sampler, through the azimuth, elevation, and extension motors, can be driven in 0.1- or 2.0-second steps left and right, up and down, and radially in extension and retraction. Figure 3 shows the area that can be reached on a nominal surface.

Commands. Spacecraft commands listed in 


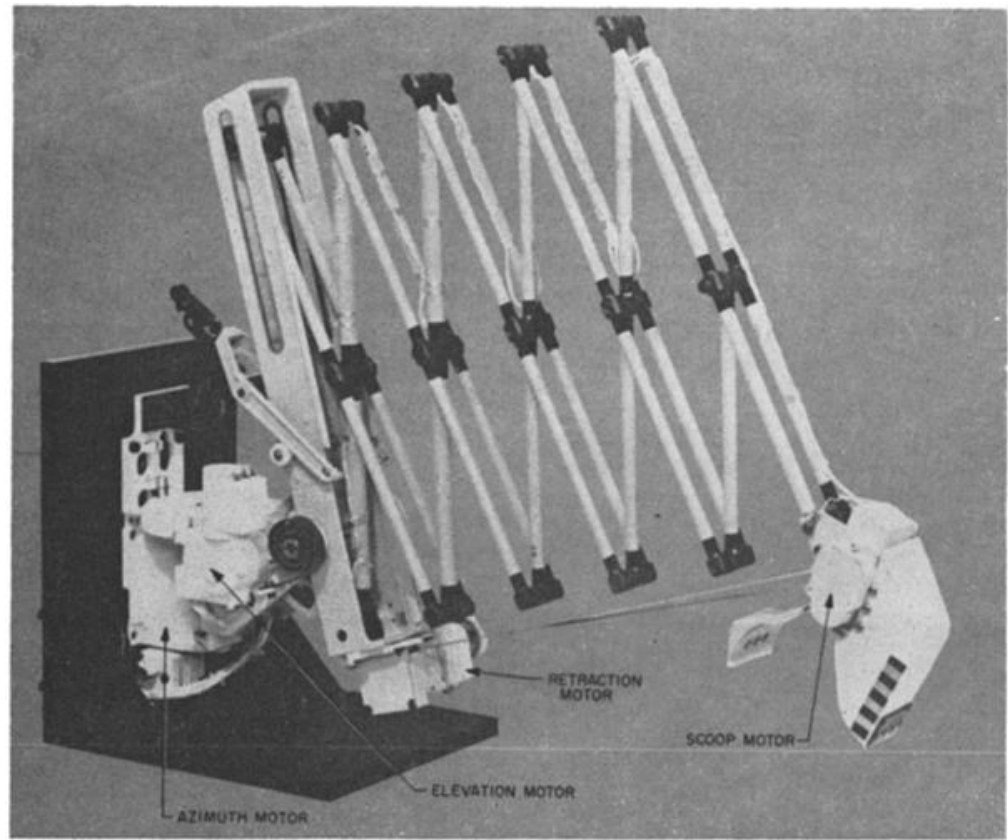

Fig. 1. Surface sampler on test stand, partially extended.

Table 1 provide all surface-sampler subsystem operations. The heater commands are self-explanatory, as are the power on and off commands. The zero- and one-level input commands are used to generate functional commands within the auxiliary electronics unit. Table 2 provides a dictionary of functional commands so generated. To command a single surface-sampler motion requires a minimum of five commands; a series of any given motions requires multiple commands [Rouze et al., 1968]. For operational convenience, as well as for reducing the chances of operational error, command tapes are used to transmit the correct sequence of spacecraft commands.

A special-purpose command tape was used in the performance of several bearing tests during Surveyor 7 lunar operations. The command tape designated 907, first sets the 2.0-second timing mode and loads the command to lower the surface sampler. Then, the execute and power off commands, separated by exactly 0.5 second, are transmitted; this provides the surface sampler with the capability of applying loads to the surface for 0.5 second. Command tape 907 continues, changing the spacecraft telemetry mode, taking a television picture, changing back to the original telemetry mode, and repeating the entire sequence. Figure 4 presents a force-versuspenetration plot of such a bearing test.

Telemetry and data display. During surfacesampler lunar operations, telemetry from the spacecraft is displayed in several ways. A computer (Univac 1219) processes spacecraft telemetry and provides a cathode-ray tube display. Selection of the proper format causes data pertinent to the surface-sampler operations to be displayed. Teletype outputs provide command confirmation, and computer line printers provide hard copy data, again on a selectable format bașis.

The motor current is assigned five symmetrically positioned commutator frames; other pertinent data (voltage, temperature, etc.) are assigned a single frame. This provides motorcurrent data at 50-msec intervals and other data at 250-msec intervals at the highest spacecraft telemetry bit rate ( $4400 \mathrm{bits} / \mathrm{sec})$. For a 2-second motor command, nominally 40 motorcurrent samples are received; this sampling interval is apparent in the plot of Figure 5 .

A multichannel strip chart recorder (Brush recorder) provides real-time plots of motor current for evaluation of surface-sample perform- 
ance. The command register status and poweron/power-off status are also displayed on this recorder.

To assist in post-mission analyses of surfacesampler performance, the motor-current data are further processed and plotted (after the mission) for comparison with calibration data. An example of such a plot is shown in Figure 5. In addition to plotting the motor-current values, this output includes temperatures, bus voltage, average value of motor current, and an average of the motor current in which the first four samples in a given burst are ignored. These first four samples indicate a motor starting transient.

Calibration. Shortly before launch, the surface-sampler subsystem calibration was performed at Cape Kennedy, Florida. At a normal voltage of 22 volts the motor current required to drive the surface sampler against a series of forces was recorded for this calibration. The opposing force was varied in controlled steps

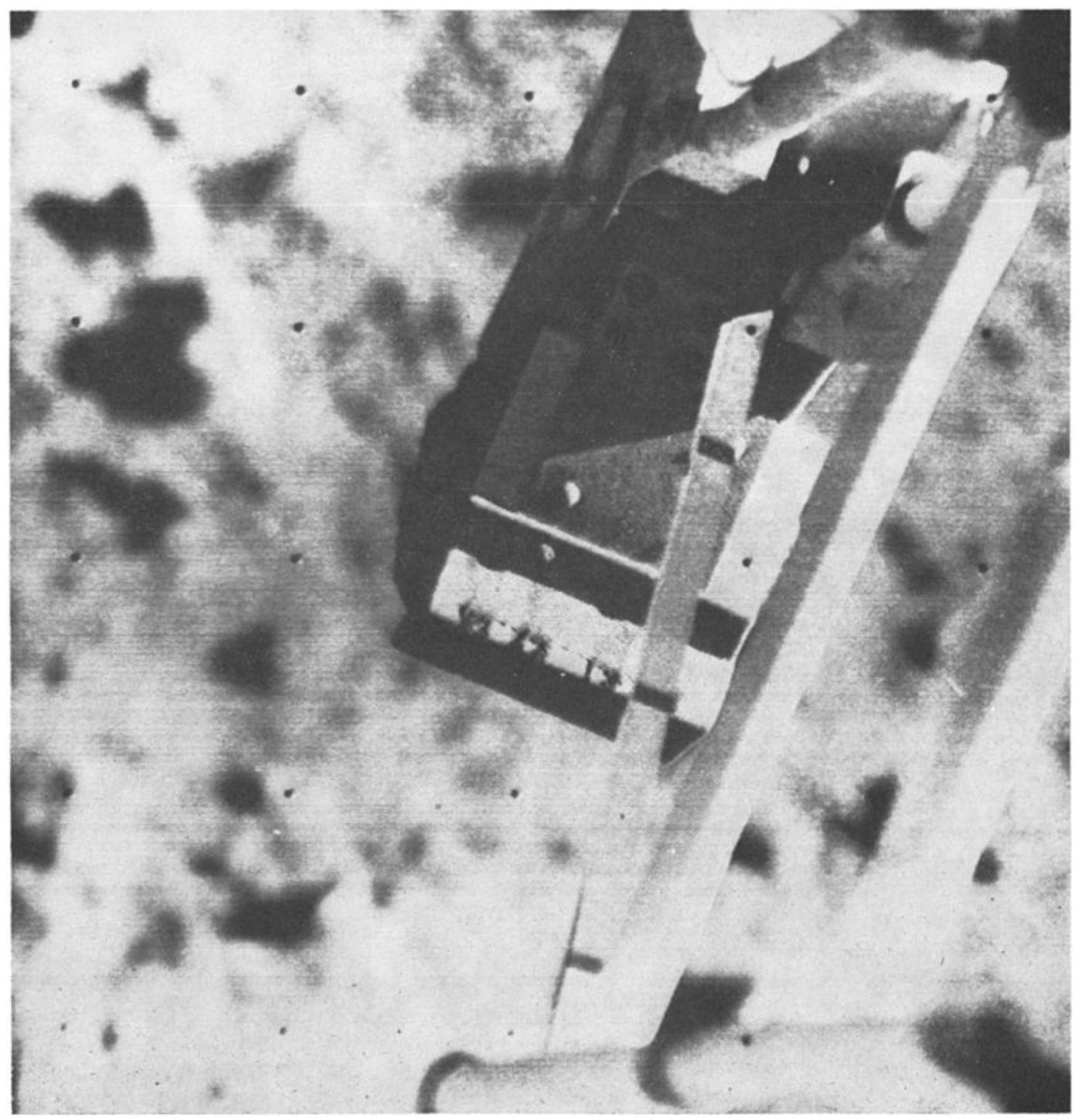

Fig. 2. Surface-sampler scoop holding rock $A$. Note that the rock is slightly larger than the width of the scoop. 


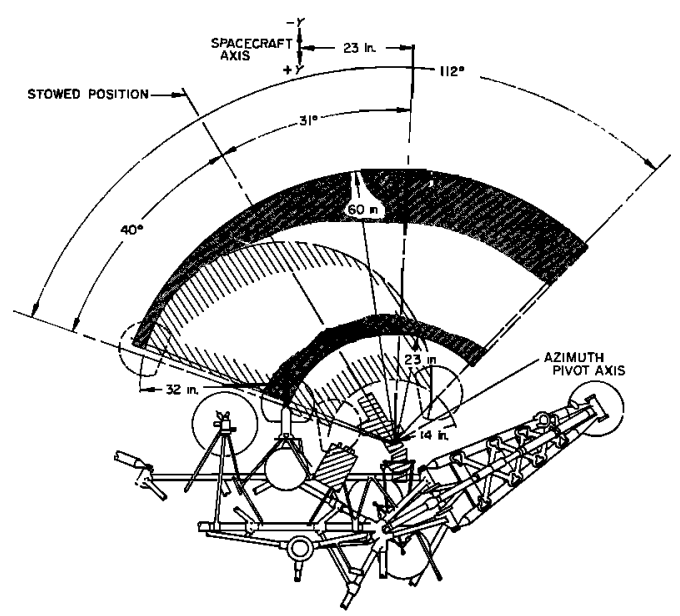

Fig. 3. Plan view of surface-sampler area of operations for a nominal surface. The cross hatching indicates the area within which the $\alpha$-scattering instrument sensor head can be manipulated by the surface sampler.

from zero up to a force that stalled the drive motor. Both retraction, or trenching mode, and lowering, or bearing mode, calibrations were performed, each at extension distances of 106 and $148 \mathrm{~cm}$. The motor-current data were re-

TABLE 1. Surface Sampler Subsystem Commands

Spacecraft

Command Designation Function Performed

\begin{tabular}{|c|c|c|}
\hline 0131 & $\begin{array}{l}\text { Power on/ } \\
\text { execute }\end{array}$ & $\begin{array}{l}\text { Turns subsystem power } \\
\text { on; if power is on, } \\
\text { executes the command } \\
\text { standingin the register. }\end{array}$ \\
\hline 0132 & $\begin{array}{l}\text { Digital } \\
\text { one input }\end{array}$ & $\begin{array}{l}\text { Enters a one-level input } \\
\text { to the command de- } \\
\text { coder shift register. }\end{array}$ \\
\hline 0133 & $\begin{array}{l}\text { Digital } \\
\text { zero input }\end{array}$ & $\begin{array}{l}\text { Enters a zero-level input } \\
\text { to the command de- } \\
\text { coder shift register. If } \\
\text { the register is full, a } \\
\text { zero-level input clears } \\
\text { the register. }\end{array}$ \\
\hline 0134 & Power off & $\begin{array}{l}\text { Turns subsystem power } \\
\text { off. Turning power } \\
\text { off automatically re- } \\
\text { sets the register and } \\
\text { sets fine-timing mode. }\end{array}$ \\
\hline 0616 & Heater off & $\begin{array}{l}\text { Turns off power to aux- } \\
\text { iliary thermal control. }\end{array}$ \\
\hline 0614 & Heater on & $\begin{array}{l}\text { Turns on power to aux- } \\
\text { iliary thermal control. }\end{array}$ \\
\hline
\end{tabular}

TABLE 2. Command Glossary

Digital

Input

Function $\begin{array}{ll}0111 & \text { Set fine timing }(0.1 \mathrm{sec}) \\ 0000 & \text { Set coarse timing }(2.0 \mathrm{sec}) \\ 1101 & \text { Enable squib firing } \\ 0101 & \text { Enable squib firing (backup) } \\ 0011 & \text { Release mechanism (fires squib) } \\ 1111 & \text { Disable squib firing (protection of circuits) } \\ 1001 & \text { Open scoop } \\ 1110 & \text { Close scoop } \\ 1000 & \text { Release clutch } \\ 1010 & \text { All motors off } \\ 0001 & \text { Extend } \\ 0110 & \text { Retract } \\ 1011 & \text { Left azimuth } \\ 1100 & \text { Right azimuth } \\ 0010 & \text { Lower } \\ 0100 & \text { Elevate }\end{array}$

corded by a Univac 1219 computer, and printouts were provided in the same format as the flight data. Plots of the current pulses were also processed. For quick-look analysis in real time, a plot of average motor current versus force was used. A typical plot of a bearing calibration test at full extension is given in Figure 6.

Operations. The basic operations of the surface sampler are bearing, trenching, picking, and lifting of objects. A bearing test can be performed with the scoop door open, thus presenting a narrow blade edge to bear on the surface, or with the scoop closed, to present a $2.5-$ by $5.1-\mathrm{cm}$ bearing plate. Bearing tests are performed by selecting a test site from the television pictures, positioning the scoop above the point of interest, and commanding the lowering of the scoop. This sequence can be accomplished with several 2.0-second commands until a stall condition is reached, or by using the special command tape 907 described above to provide a series of 0.5 -second commands. A 0.1 -second command is not used in a sequential bearing test because the motor-current readout occurs at 50-msec intervals at the highest spacecraft telemetry bit rate available. The 0.1 -second command thus does not afford sufficient current or force samples for a meaningful test.

A trenching test is performed by driving the scoop into the surface (normally, but not necessarily, with the scoop door open) in the same manner as in a bearing test. After the elevation 
motor is stalled, a series of retraction commands pulls the scoop back through the soil, digging a trench the width of the scoop $(5.1 \mathrm{~cm})$. Motorcurrent data yield information about the strength of the soil; current measurements during successive passes through a trench provide information about the variation of strength with depth.

A picking, or impact, test is performed by positioning the scoop above a desired surface point or rock and releasing the solenoid-operated elevation drive clutch. This allows the mechanism to rotate freely at the elevation axis, so that a torque spring and gravitational acceleration cause the scoop to strike the surface.

Manipulating, grasping, or lifting objects with the surface sampler is the most time-consuming type of operation. Such an effort requires careful study of television pictures before and after any command sequence to evaluate the surfacesampler response and to select further commands to achieve the desired result.

Figure 7, which is intended as an operational aid, is a plot of the surface-sampler area of operations, with a diagram of the surface areas viewed by the television camera at various camera azimuth and elevations. From the television data, the position of a selected object within the surface-sampler area can be plotted, and the commands required to move the surface sampler to the object may be chosen.

\section{Mission Description}

Engineering performance. During Surveyor 7 lunar operations, the performance of the sur-

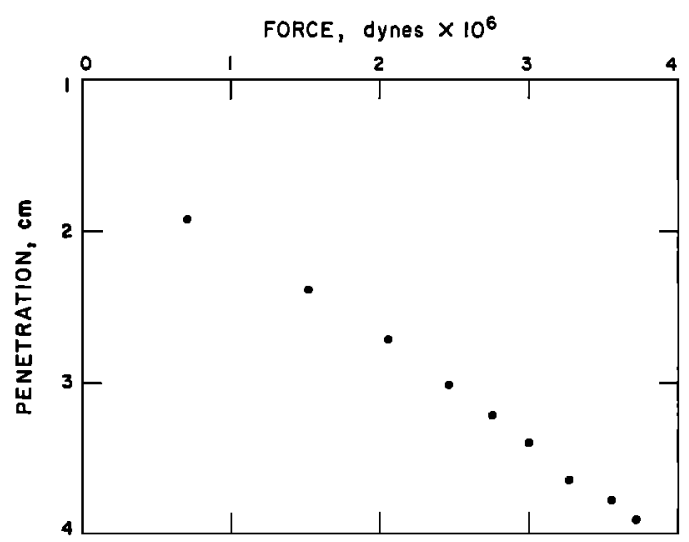

Fig. 4. Force versus penetration curve for bearing test 2 .

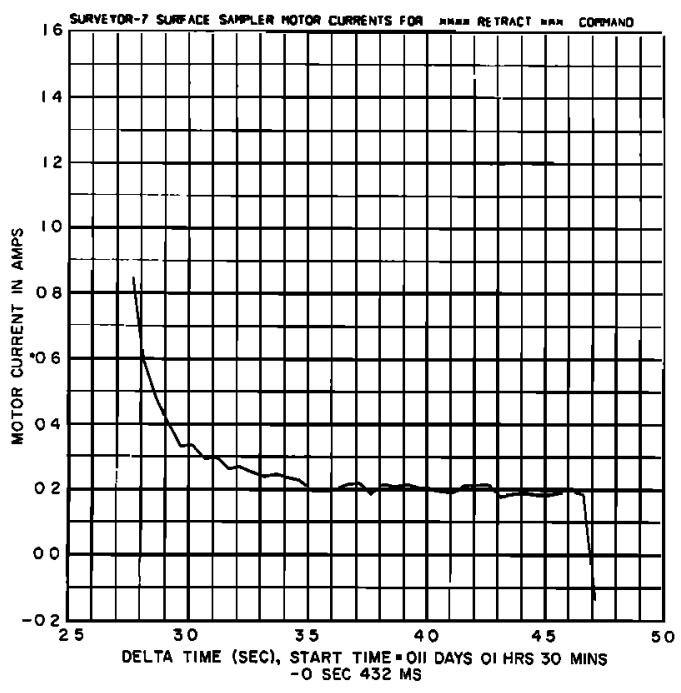

Fig. 5. Typical computer output plot of postmission processed surface-sampler motor current.

face-sampler subsystem was flawless under a wide range of operating conditions. Figure 8 shows the temperatures of the elevation and retraction motors and of the auxiliary electronics unit throughout the first lunar day. During the critical period around lunar noon (days 015 through 018), the surface sampler was operated to provide shade for the thermal-control surfaces of the $\alpha$-scattering instrument's sensor head. Without this shade, it is possible that the temperature of the sensor head would have exceeded its survival limits.

Several of the shading operations were performed when the auxiliary electronics unit of the surface sampler was above its upper operating limit. In these operations, the motors operated normally at temperatures up to $180^{\circ} \mathrm{F}$.

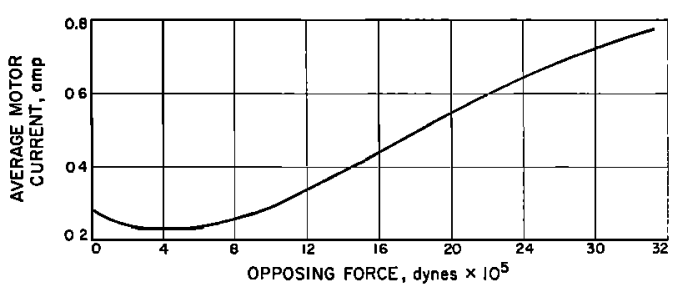

Fig. 6. Calibration curve produced from preflight calibration performed at Cape Kennedy, Florida. This curve shows force versus current for the bearing test mode with the surface sampler at 147-cm extension. 


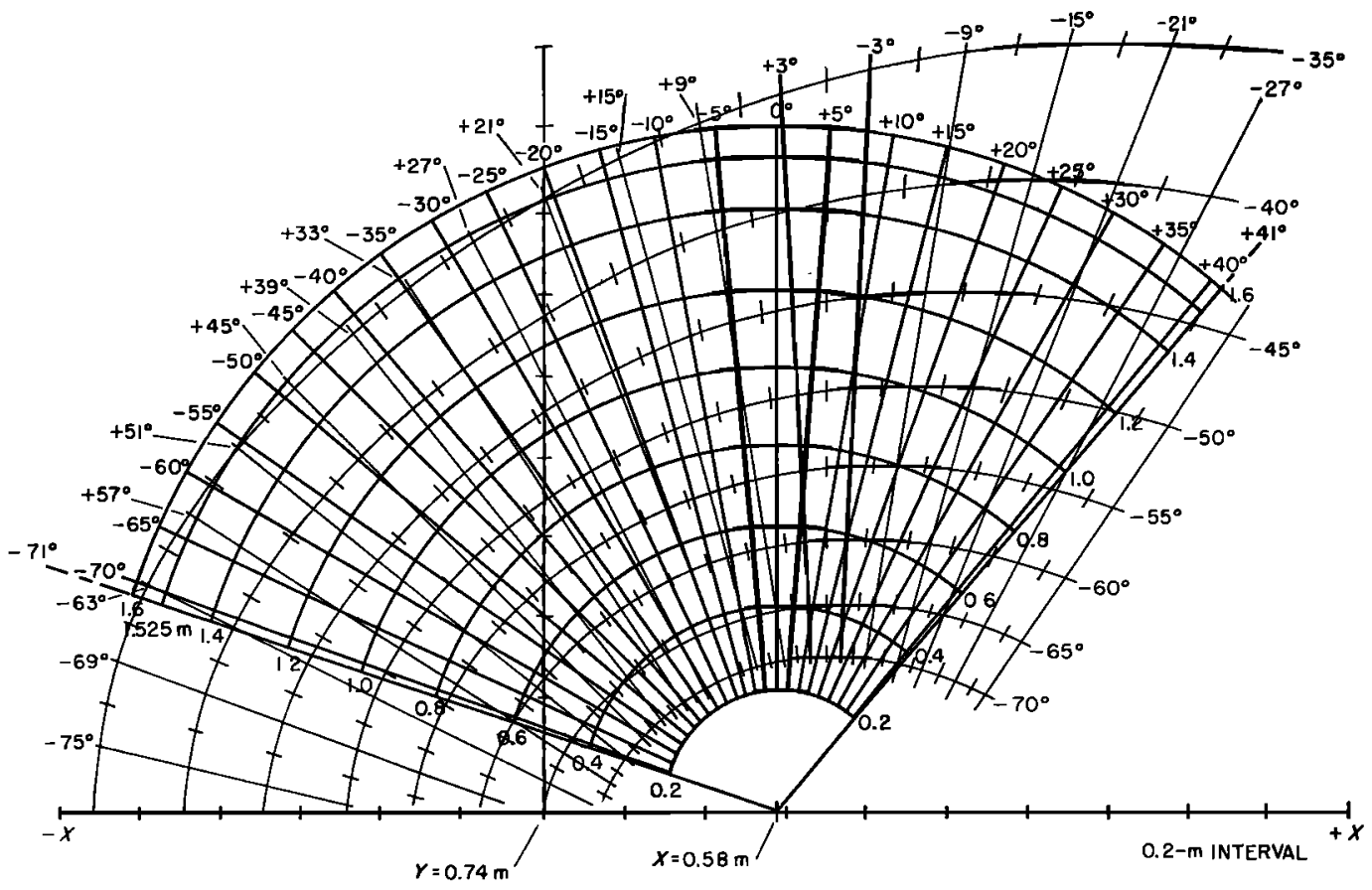

Fig. 7. Operational aid used for selecting television camera position to view specific areas of surface-sampler operations.

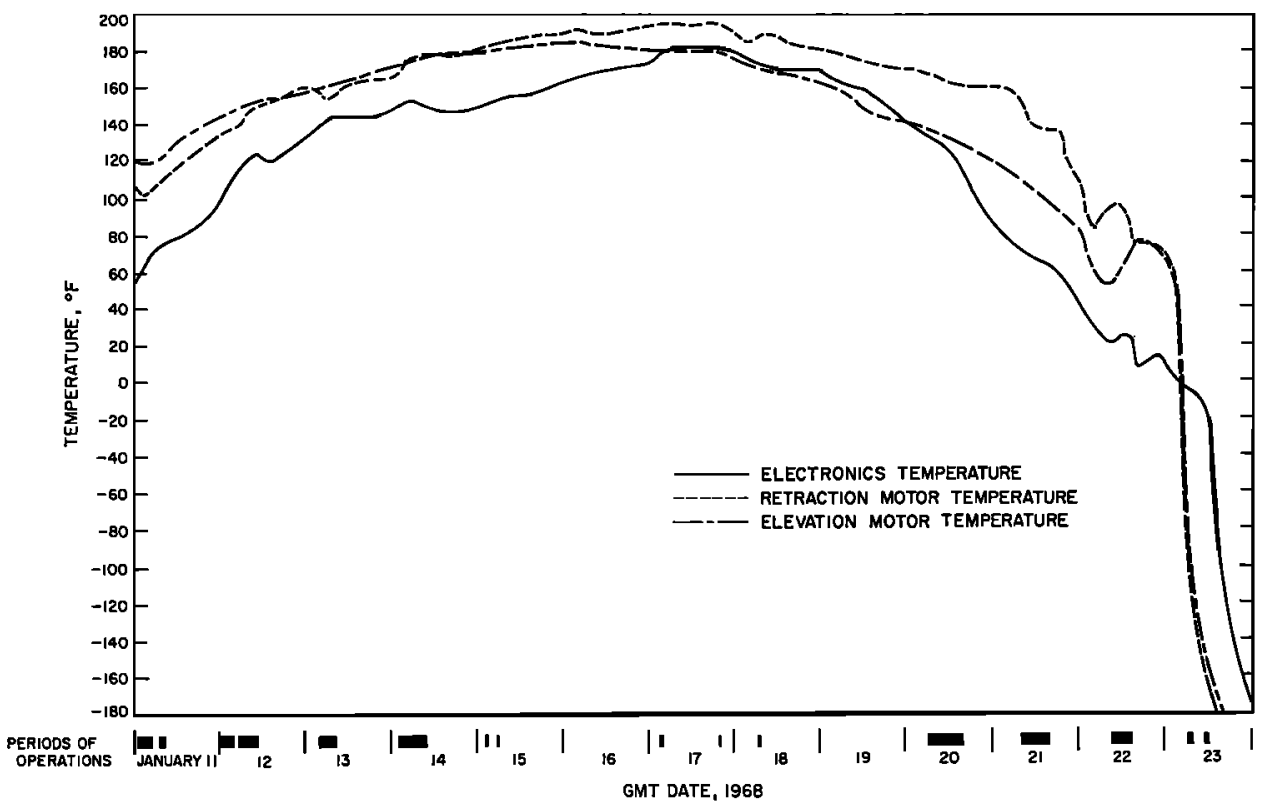

Fig. 8. First lunar day surface-sampler temperatures. Periods of operation are noted by the bars at the bottom of the figure. 
On the other hand, at one stage during postsunset operations, retraction forces were applied to the lunar surface at a time when the retraction motor temperature was $-167^{\circ} \mathrm{F}$.

Throughout the mission the command decoding and telemetry outputs of the auxiliary electronics unit performed as designed. Table 3 gives the total commands and operating durations for the subsystem during the first lunar day. Of the 36 hours and 21 minutes of operation time, a total of 8 hours and 45 minutes was used in deploying or redeploying the $\alpha$-scattering instrument.

\section{Lunar Operations: First Lunar Day}

Initial operations for the surface sampler were not scheduled to begin until the $\alpha$-scattering instrument had been deployed to the lunar surface, thus ensuring an undisturbed lunar surface as the first sample. This delay would also provide adequate television coverage of the area for planning tests before initiation of activities. This preliminary television coverage is shown in Figure 9. The attempt to deploy the sensor head of the $\alpha$-scattering instrument to the lunar surface by normal means was unsuccessful. This failure led to decisions to start surface-sampler activities and, after certain minimal data were acquired, to attempt to free the $\alpha$-scattering instrument.
Day 011. Surveyor 7 surface-sampler operations started with the initial power-on command at $01 \mathrm{~h} 00 \mathrm{~m} \mathrm{28s} \mathrm{GMT;} \mathrm{after} \mathrm{four} \mathrm{2.0-}$ second extend commands, the first television picture verifying proper response was received at 01h 22m 35s GMT. This initial checkout procedure continued with motor current and video verification that the azimuth, elevation, and extension drive systems were functioning properly. Initial contact with the lunar surface occurred at bearing point 1, shown in Figures 10 and 11. This bearing test was accomplished by driving the scoop down two 2.0-second steps. Bearing point 2 , located to the left of bearing point 1 and at a greater extension distance (Figure 10), was the first test to use command tape 907 . This test is shown in Figure 12a.

After these initial bearing tests, the first attempt was made to free the sensor head from its background position. In the hope that the problem was a minor frictional one, the attempt consisted of light taps applied to the circular plate of the sensor head. Although television pictures did show that the $\alpha$-scattering instrument moved and swayed at the end of its nylon cord, the instrument did not lower.

Day 012. Surface-sampler operations on day 012 started with bearing point 3 (Figure 10). This test consisted of a 2.0 -second down command in which surface contact was made during

TABLE 3. Surface-Sampler Subsystem Performance Summary for First Lunar Day

\begin{tabular}{|c|c|c|c|c|}
\hline $\begin{array}{c}\text { Day of } \\
1968\end{array}$ & Power on Time & $\begin{array}{l}\text { Number of Commands } \\
\text { Addressed to Surface } \\
\text { Sampler }\end{array}$ & $\begin{array}{l}\text { Number of Surface- } \\
\text { Sampler Functions } \\
\text { Performed* }\end{array}$ & $\begin{array}{l}\text { Number of Surface- } \\
\text { Sampler Mechanism } \\
\text { Motions Commanded }\end{array}$ \\
\hline 011 & $03 \mathrm{~h} 59 \mathrm{~m}$ & 806 & 371 & 184 \\
\hline 012 & $06 \mathrm{~h} 30 \mathrm{~m}$ & 1,581 & 766 & 426 \\
\hline 013 & $03 \mathrm{~h} 29 \mathrm{~m}$ & 1,499 & 853 & 561 \\
\hline 014 & $03 \mathrm{~h} 43 \mathrm{~m}$ & 2,008 & 1,190 & 828 \\
\hline 015 & $00 \mathrm{~h} 09 \mathrm{~m}$ & 73 & 38 & 22 \\
\hline 016 & $00 \mathrm{~h} 00 \mathrm{~m}$ & 0 & 0 & 0 \\
\hline 017 & $00 \mathrm{~h} 10 \mathrm{~m}$ & 42 & 18 & 6 \\
\hline 018 & $00 \mathrm{~h} 03 \mathrm{~m}$ & 21 & 9 & 3 \\
\hline 019 & $03 \mathrm{~h} 07 \mathrm{~m}$ & 1,364 & 898 & 590 \\
\hline 020 & $05 \mathrm{~h} 35 \mathrm{~m}$ & 2,006 & 1,022 & 596 \\
\hline 021 & $04 \mathrm{~h} 37 \mathrm{~m}$ & 1,289 & 713 & 463 \\
\hline 022 & $04 \mathrm{~h} 01 \mathrm{~m}$ & 1,830 & 1,017 & 685 \\
\hline 023 & $00 \mathrm{~h} 58 \mathrm{~m}$ & 120 & 61 & 33 \\
\hline Total & $36 \mathrm{~h} 21 \mathrm{~m}$ & 12,639 & 6,956 & 4,397 \\
\hline
\end{tabular}

* Functions performed include such operations as set timing mode, clear register, etc.; they did not necessarily result in surface-sampler motions. 


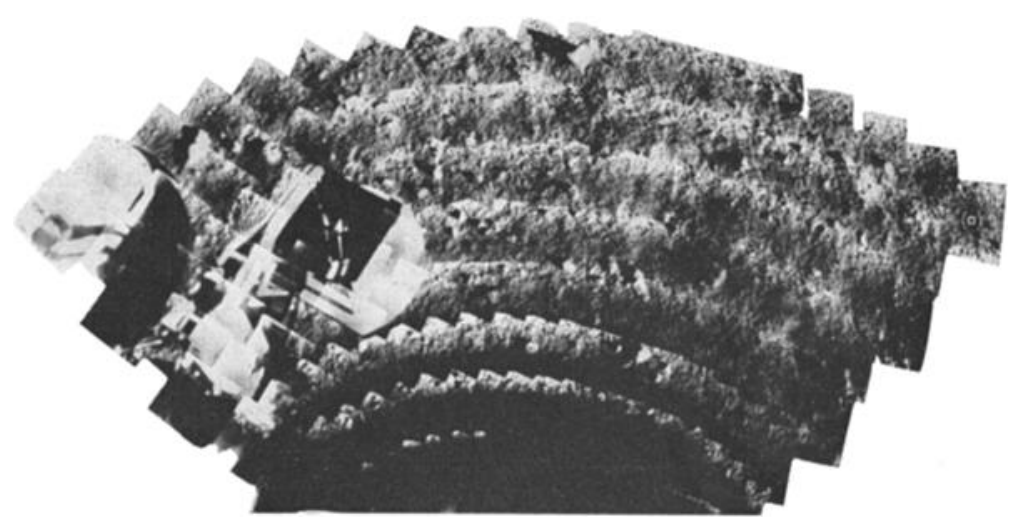

Fig. 9. Mosaic of Surveyor 7 pictures showing the surface-sampler area of operations before activities began.

the last one-third of the travel. The elevation motor was not stalled, thereby giving data on the initial penetration only.

Bearing point 4 followed at the same azimuth position at a greater extension (Figure 10). Again, command tape 907 and eight 0.5 -second steps were used. Bearing point 4 is seen in Figure $12 b$.
Bearing test 5 was performed by moving left and locating at the position noted in Figure 10. This bearing test was performed by using a single 2.0-second lower command and by attempting to contact the surface during the steady-state part of the travel. This contact was achieved, and the result is shown in Figure 12c.

The initial pickup of rock A (Figure 12d)

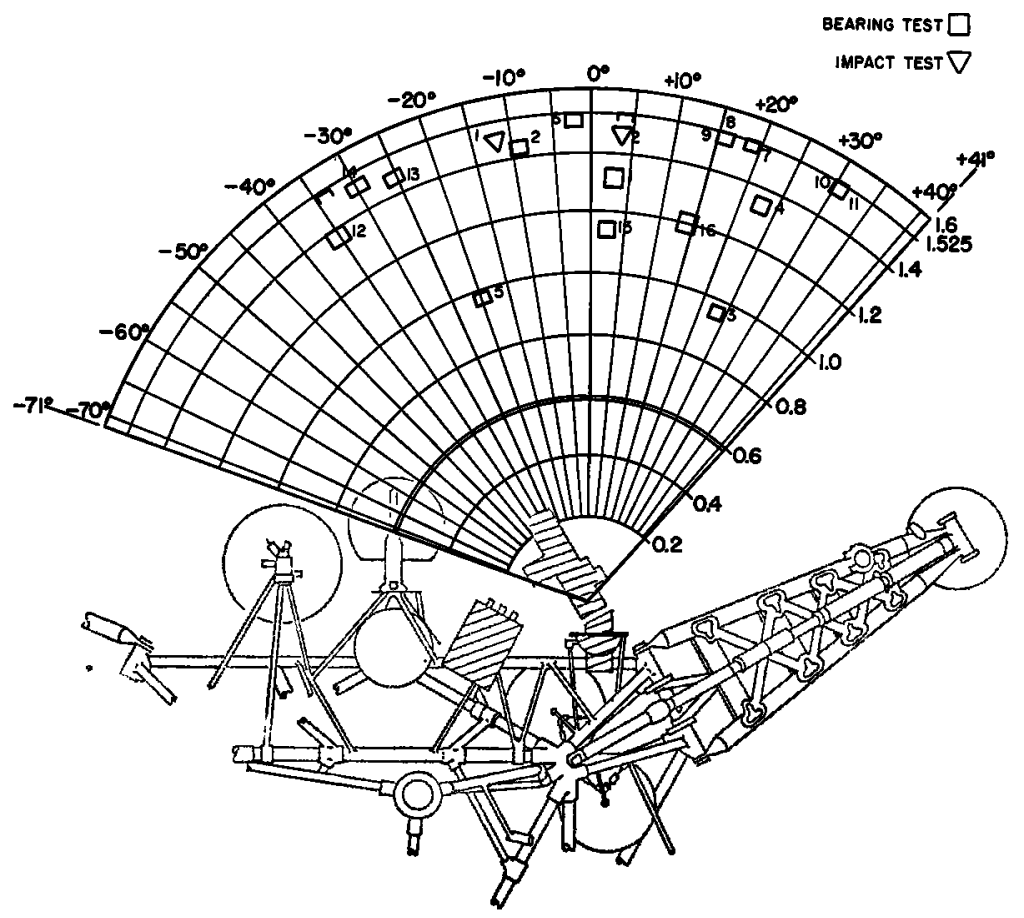

Fig. 10. Plan view of surface-sampler operations showing location of bearing and impact tests performed. 
followed bearing test 5 . The rock was lifted and motor-current data taken to give weight information. The rock was dropped after this first pickup, and it landed at position $\mathrm{A}^{\prime}$ shown in Figure 16. Figure 2 shows the rock in the scoop before it was dropped.

In the Surveyor Experiment Test Laboratory, an analysis of the $\alpha$-scattering instrument's position led to a plan for further attempts to free the sensor head. The surface sampler was positioned near the right side of the sensor head, and by a series of extend and left azimuth steps the sampler gradually rotated the sensor head and moved it left until it was in contact with the helium tank. In this position (shown in Fig- ure 13) it appeared that the $\alpha$-scattering instrument was wedged between the helium tank, the surface-sampler scoop, and some part of the $\alpha$ scattering instrument's standard-sample bracket. Under this condition, surface-sampler lower commands applied a downward force to the $\alpha$ scattering instrument, which came free and moved down several centimeters. This allowed the scoop to be placed on top of the $\alpha$-scattering instrument and a direct downward force to be applied to it. The thermal mirror on the sensor head was an aid in positioning the scoop and, as can be seen in Figure 14, afforded a view of the scoop interior. The $\alpha$-scattering instrument was lowered to a point at which it

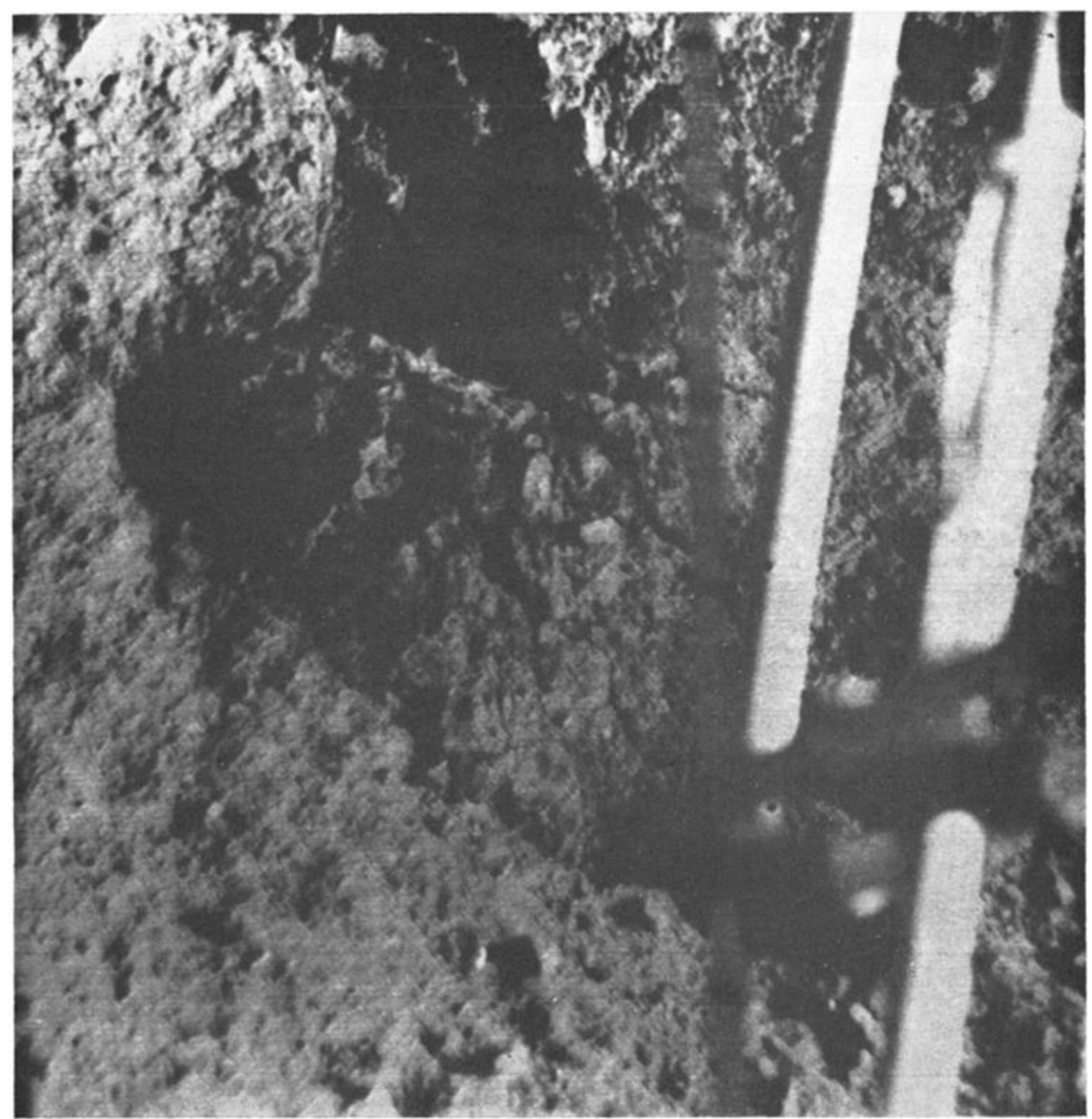

Fig. 11. Bearing test 1. This picture shows the first surface-sampler contact with the lunar surface at the Surveyor 7 landing site. 


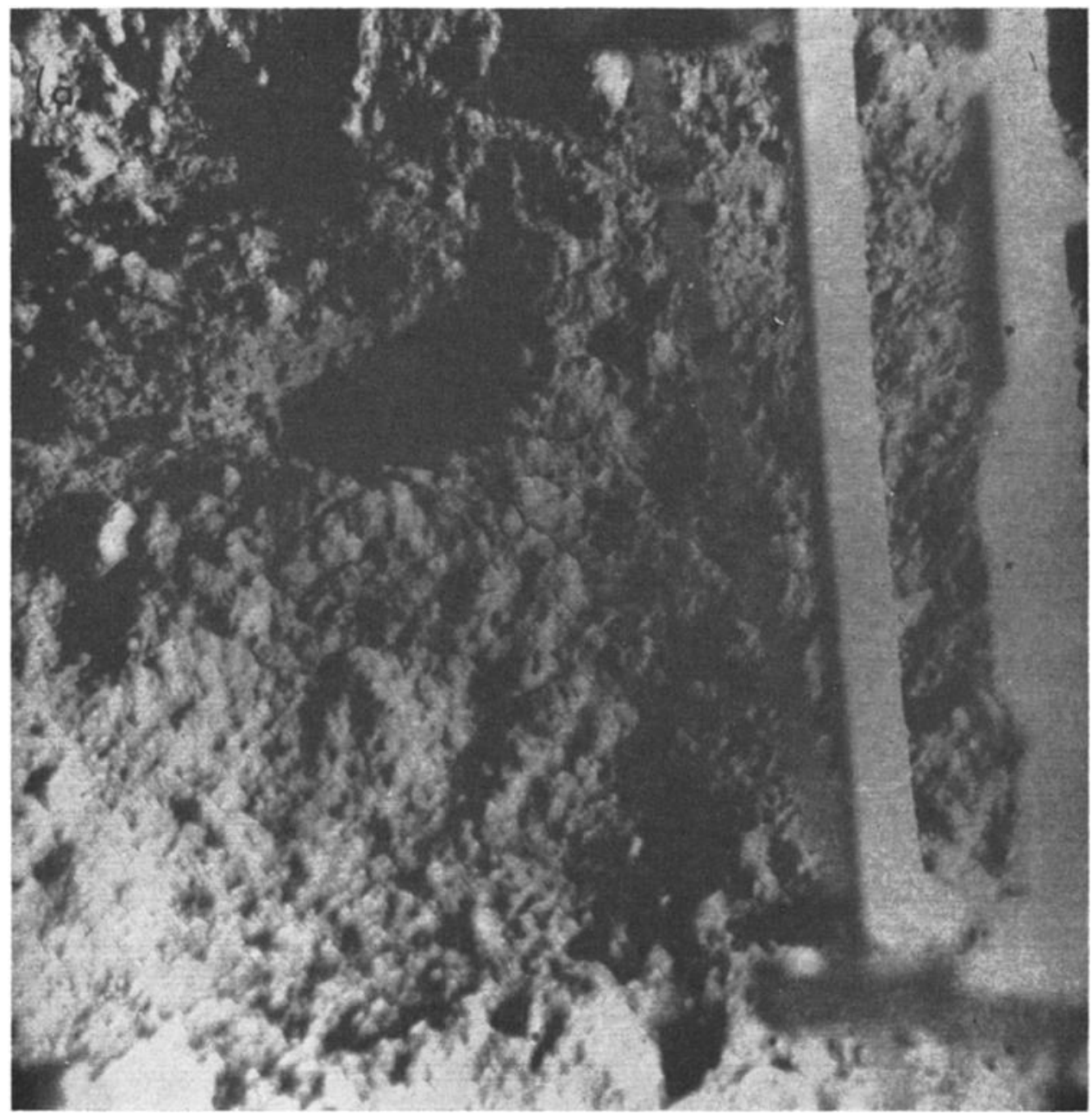

Fig. 12a. Results of surface-sampler bearing test 2.

appeared to be on the surface, but a short test of the instrument counting rate showed that it was not. The surface sampler was again positioned above the sensor head and continued to force it down until it was on the surface in the position shown in Figure 15.

Day 013. The first activity on day 013 was an attempt to reach rock B (Figure 16) and lift it. Two attempts were made, and verified that the rock was beyond the maximum extension distance for the surface sampler. In further attempts to weigh another rock (in addition to rock $\mathrm{A}$ ), rock $\mathrm{C}$ was picked up (Figure 17), but in the course of being elevated for weighing it slipped out of the scoop. Though it was not immediately apparent, later television surveys revealed that rock $\mathrm{C}$ had landed at location $\mathrm{C}^{\prime}$ in Figure 16.

Because the sun azimuth was progressing across the surface-sampler area, the first trenching operation was performed at the extreme right azimuth position. The position choice was also influenced by a desire not to disurb the surface near the sensor head of the $\alpha$-scattering instrument and by the operational convenience of azimuth positioning accuracy for possible further passes through the trench. Trench 1 , shown in Figure 17, was dug by going to the right stop, applying two 2.0-second lower steps, at which point the surface sampler was stalled, and retracting six 2.0-second steps. The scoop was then lifted clear of the surface and extended 
back to the head of the trench. A second pass through the trench required a single lower command, and after four 2.0 -second retract commands, the surface sampler stalled. Two additional retract commands failed to break it loose.

The surface sampler was extended and lifted clear of the trench. Positioning the scoop to cast a shadow on the sensor head completed operations for day 013 .

Day 014. In a further attempt to obtain a large rock for weighing, (an attempt that was reinforced by a desire to make a rock available for analysis by the $\alpha$-scattering instrument), the operations for day 014 consisted entirely of working with rock $\mathrm{D}$ (Figure 16 and 18a). At this time in the mission, television camera and spacecraft battery temperatures were high and, in fact, dictated low-duty-cycle operations. The surface-sampler operations consisted of extending to the maximum distance at rock $D$ and closing the scoop on the rock. The rock was dislodged, as shown in Figure 18b, and attempts to lift it resulted in its slipping from the scoop. Over a total period of 7 hours attempts to move the rock closer for a better grip were unsuccessful.

Operations for the day were concluded with the repositioning of the scoop shadow on the

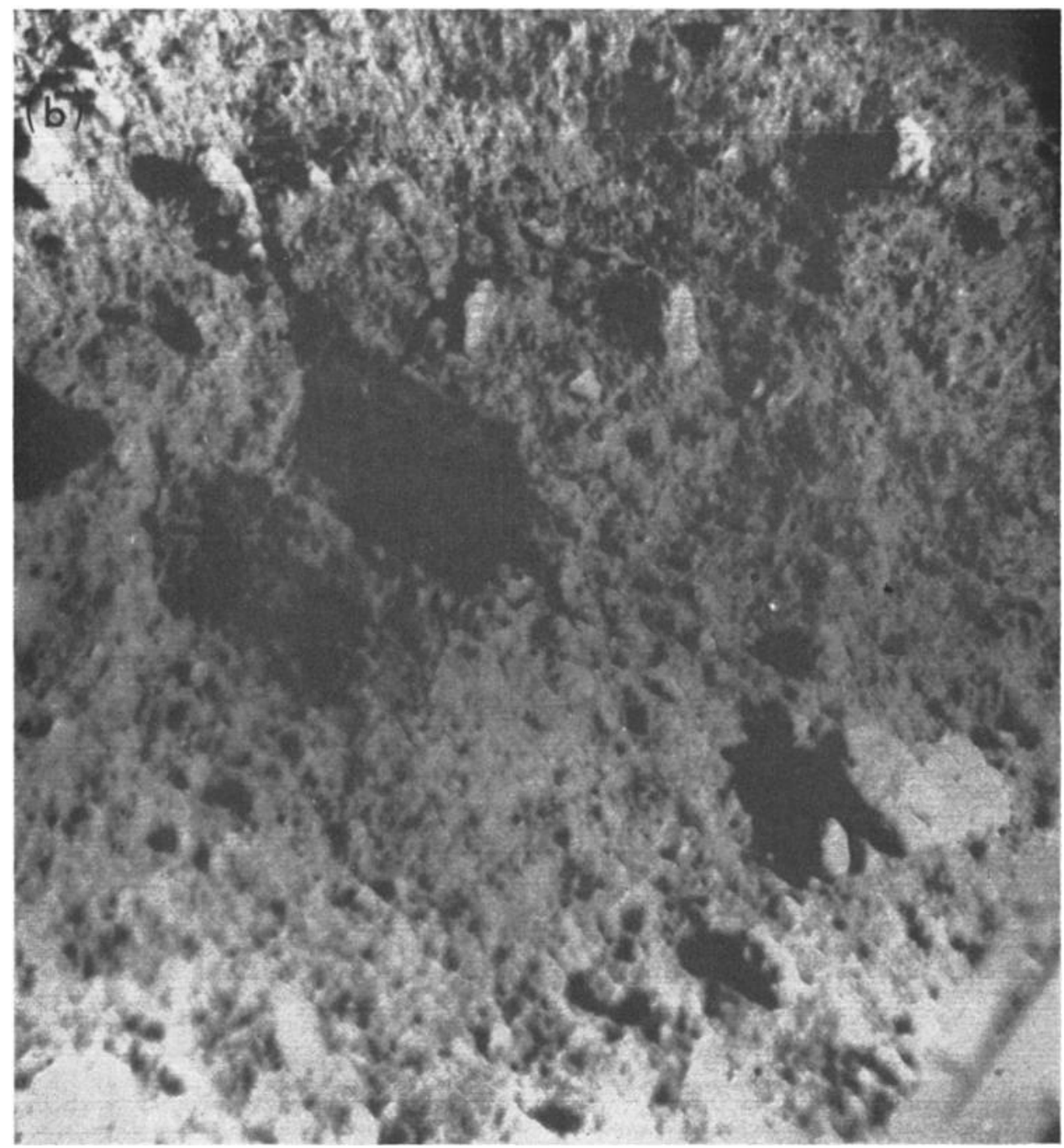

Fig. 12b. Results of surface-sampler bearing test 4 . 


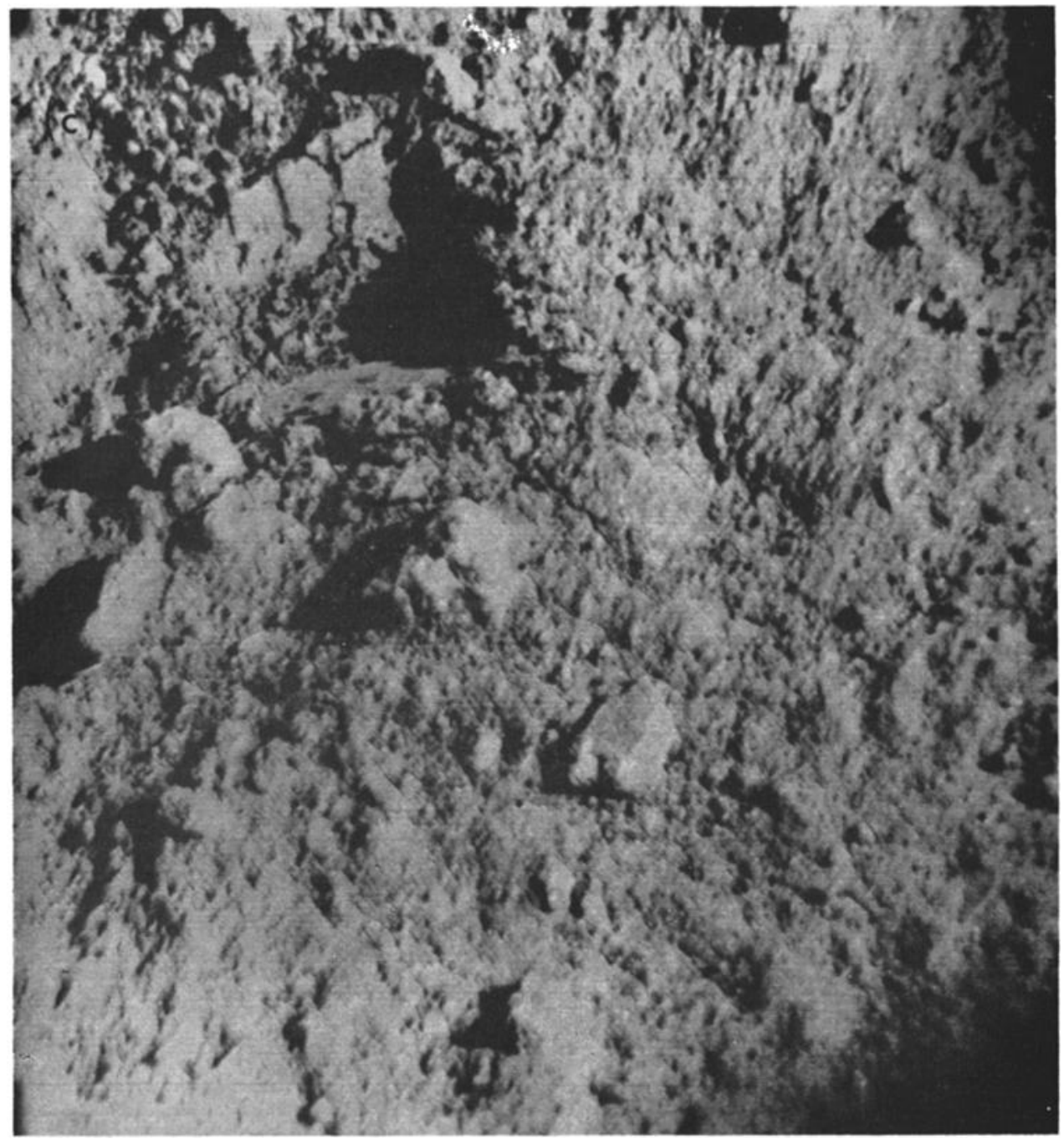

Fig. 12c. Results of surface-sampler bearing test 5 .

thermal-control surfaces of the $\alpha$-scattering instrument.

Day 015. Although the surface-sampler temperatures were high, the instrument was turned on and moved to provide continued thermal relief for the sensor head. Surface-sampler operations were not effective under the severely limiting duty cycles imposed by camera temperature.

Day 016. No surface-sampler operations were performed.

Day 01\%. The surface-sampler scoop was moved twice to shade the sensor head. A total of six surface-sampler motions were commanded for this effort (Table 3 ).
Day 018. On day 018, spacecraft temperatures still precluded effective surface-sampler operation, and activity was again limited to shading the sensor head.

Day 019. With camera duty cycles increasing and general spacecraft temperatures improving, surface-sampler operations were resumed, starting with further weighing of rock A. The rock, at position $A^{\prime}$ in Figure 16, was lifted, the motor current was recorded for weight data, and the rock was subsequently moved into the area of stereo view, by using the auxiliary mirror for stereo coverage.

Once in this area, the rock was viewed di- 
rectly by the television camera and was viewed through the stereo mirror. Subsequently, the rock was picked up in the surface-sampler scoop, and stereo pictures were obtained. After dropping the rock, additional pictures were taken at the identical camera positions, to provide before and after coverage. Analysis of these pictures provided the information on surfacesampler deflection caused by the weight of the rock.

After the weighing exercise, the rock was again picked up and transported to a third location, point $A^{\prime \prime}$ in Figure 16. This position was chosen for its proximity to the sensor head. The surface-sampler scoop was lowered to the rock at its new location, and a series of lower commands used to perform a bearing test on the rock.

From this position, the surface sampler was extended to its maximum distance; the scoop opened, and a 2.0 -second-command bearing test was performed at bearing point 6 (Figure 10). After the scoop was driven into the surface in this bearing test, a series of nine 2.0 -second retract commands completed the first pass through trench 2 (Figure 16). At the end of operations

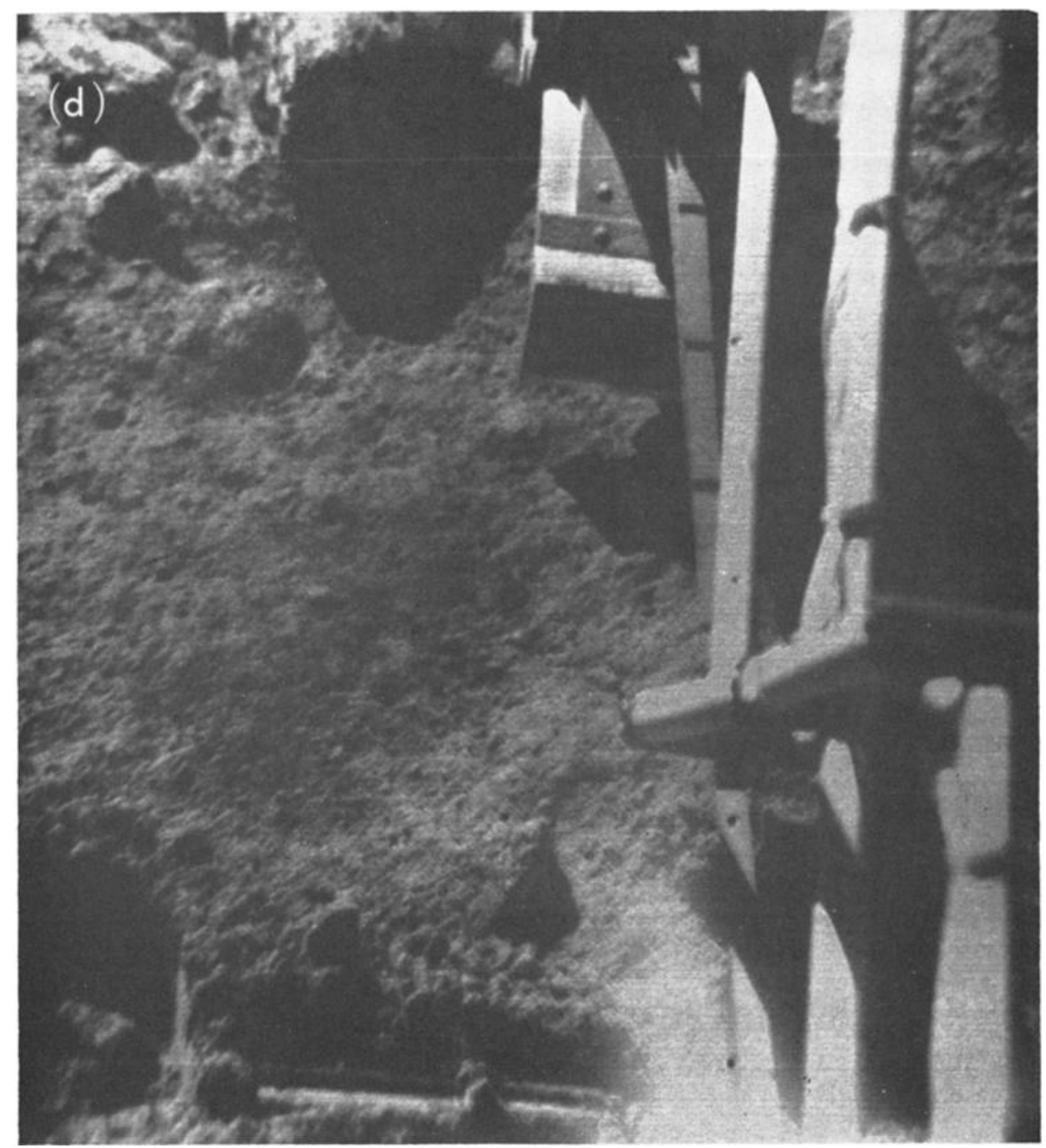

Fig. 12d. Surface-sampler bearing test 6 in progress. 


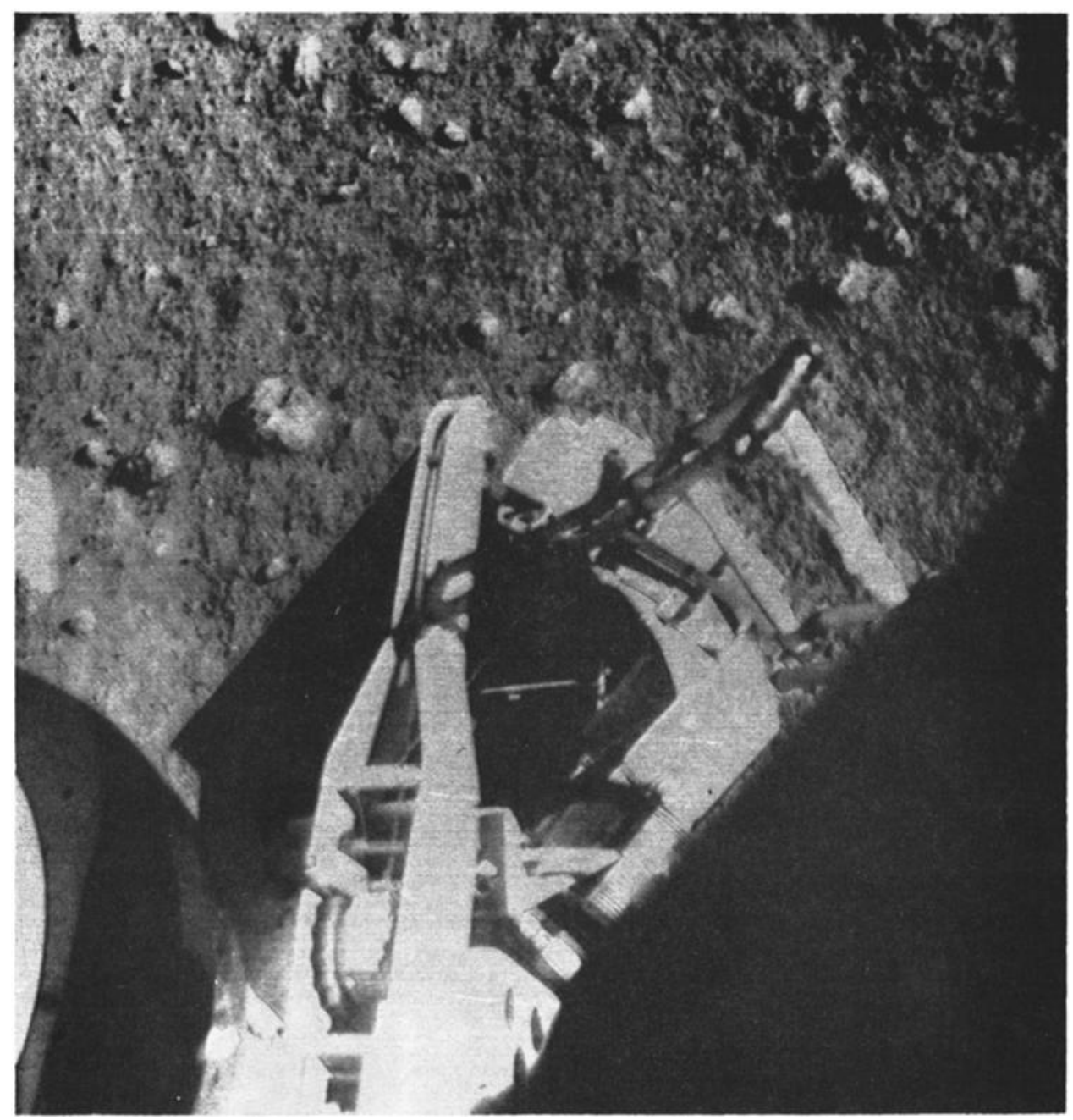

Fig. 13. The surface sampler is shown forcing the sensor head against the helium tank, preparatory to applying a downward force to free the sensor head.

on day 019, the surface sampler was left in place at the foot of trench 2 .

Day 020. At the start of day 020 operations, the surface sampler was lifted clear of its position at the foot of trench 2 , extended, and lowered into the head of the trench for a second pass through the trench. After five 2.0 -second retract commands, a second lower command was given to maintain the scoop bearing force on the bottom of the trench. Three additional coarse ( 2.0 second) retract commands completed the second pass through the trench.

After again extending to the head of the trench and lowering for the third pass through it, four 2.0-second retract commands resulted in a stalled retraction drive. A fifth retract command failed to break it free, and some maneuvering of the scoop by extending and elevating slightly before continuing the retraction was necessary to clear the subsurface object causing the stall. After twice stalling on the object, the trench was lengthened to its maximum dimension. The third pass was completed after thirteen coarse retract steps, three of which were executed under stall conditions.

At the beginning of the fourth pass, near the head of trench 2, after the first two retract commands (2.0-second timing mode), a slight 
increase in resistance was indicated by the motor-current data, and the scoop was observed to be forced laterally to the left, widening the trench as though the scoop were going around a buried obstruction. The remaining retraction met little resistance, and a total of seven 2.0second retract steps completed the effort in trench 2.

After completing trench 2, the scoop was extended and moved right to the point noted as bearing point 7 in Figure 10. With the scoop still open, a bearing test was performed by use of command tape 907. A series of seven 0.5- second commands completed bearing test 7 . Bearing tests 8 and 9 were performed at the same site, just left of bearing point 7 , as can be seen in Figure 10. Bearing test 8 was performed with the scoop closed by using command tape 907 for a total of four 0.5-second lower commands. Figures $19 a$ and $19 b$ show bearing test 8 in progress and after removal of the scoop, respectively.

Bearing test 9 was performed at the same location, after opening the scoop door. The test, shown in Figure $19 c$ and $19 d$, consisted of two 2.0-second lower commands. After the scoop

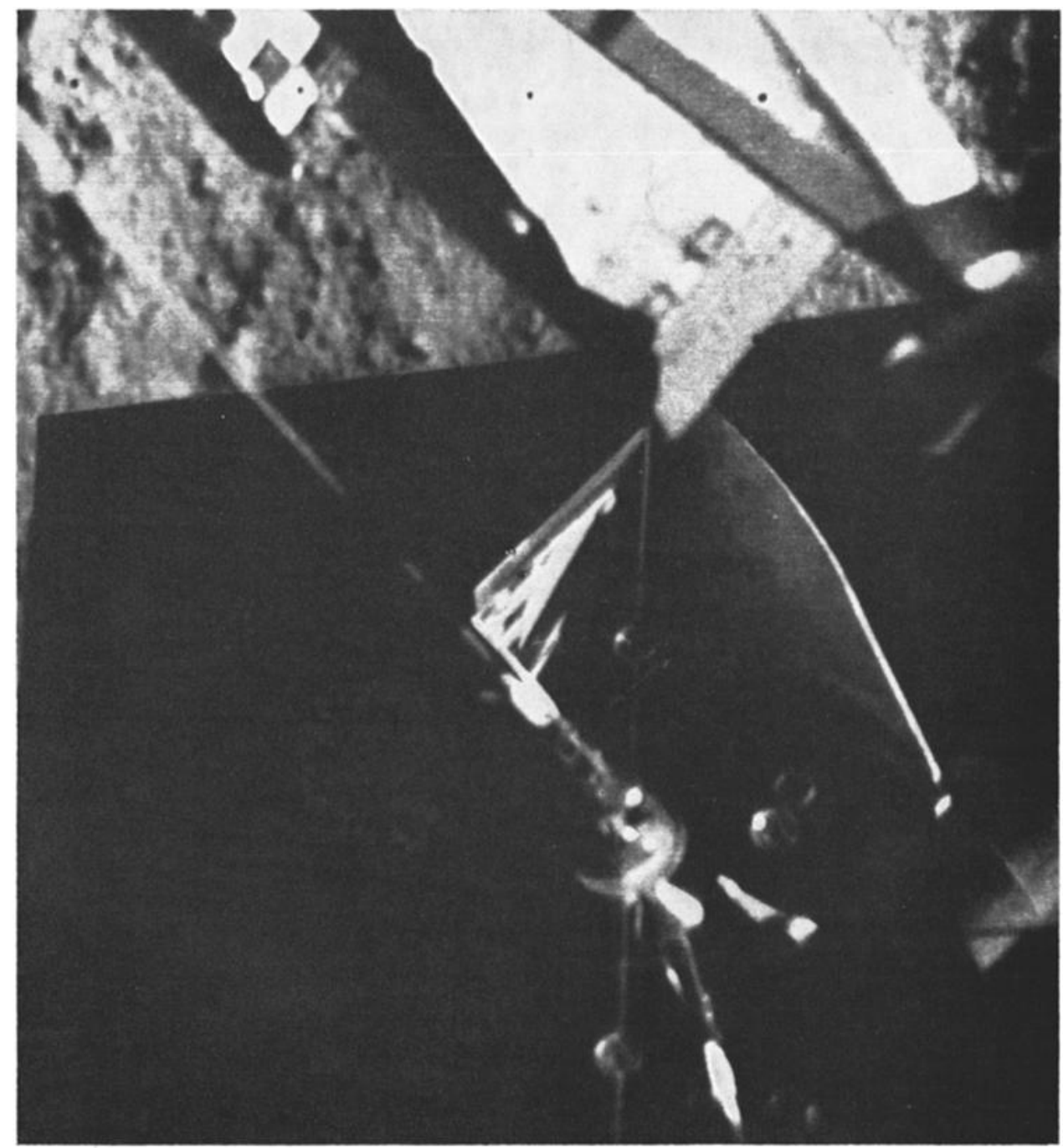

Fig. 14. The thermal radiating mirror of the sensor head affords an excellent view of the surface-sampler scoop interior when the scoop is positioned above it. 


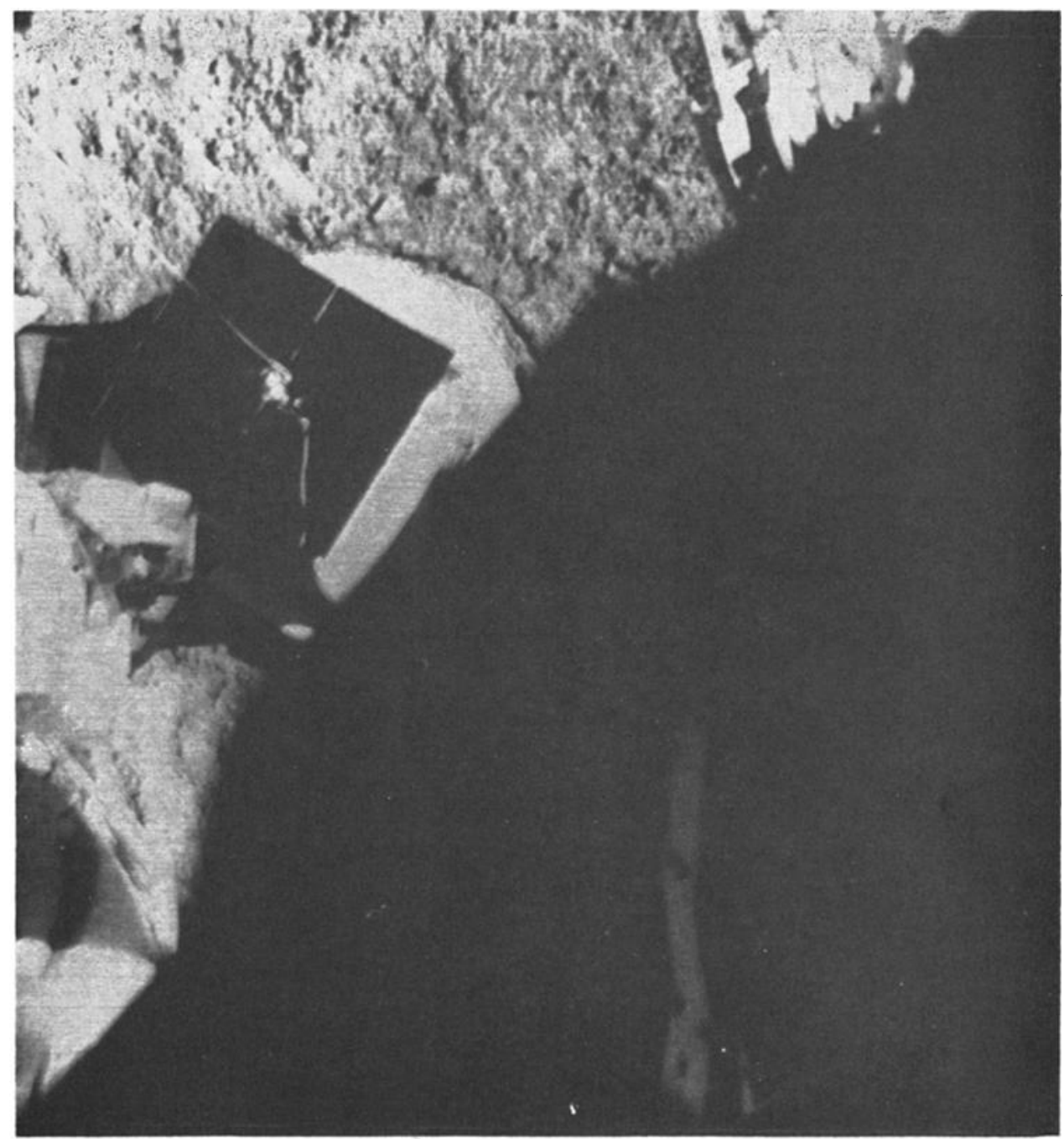

Fig. 15. The sensor head is shown on the lunar surface in position for its first analysis after the surface sampler has forced it down.

was lifted clear of bearing point 9 for examination, it was again lowered, and three 2.0 -second retract commands were executed, which resulted in trench 3, located as shown in Figure 16. At the completion of the trench, the scoop was closed, and two 2.0-second elevate commands were executed, with motor-current data to determine the weight of the soil in the scoop.

The scoop was extended to the maximum distance and moved right in preparation for bearing point 10, as located in Figure 10. As in bearing tests 8 and 9 , bearing test 10 was conducted by use of command tape 907 , resulting in six 0.5-second lower steps. This test was followed by bearing test 11, performed with the scoop open; again command tape 907 was used, which resulted in six lower commands.

Trench 4 was dug by retracting three 2.0 second steps from bearing point 11 . The area noted in Figure 16 as the magnet scrape trench was the location of operations following trench 4. The scoop was lowered to the surface with the door closed and, by a series of 2.0 -second retract commands, was dragged across the surface in a trenching mode. After three such commands, the scoop was lifted clear of the surface 
and the scoop door was opened. A rock fragment was observed, apparently adhering to the scoop door. To afford a closer television view, the scoop was elevated two 2.0 -second steps. and a narrow-angle television picture was taken (Figure 20). Subsequent attempts to move the scoop into the stereo view area for closer television study of the fragment resulted in its loss before the stereo view was achieved.

To complete operations for day 020, the scoop was again positioned to shade the sensor head.

Day 021. Operations for day 021 started with the performance of 2.0 -second elevate commands at the final position of rock $A$, noted as position $A^{\prime \prime}$ in Figure 16. These commands were executed to gather no-load motor-current data before later lift tests with the sensor head at the same position.

Operations then proceeded with the position of the scoop above the sensor head and the closIng of the scoop on the knob, or eye bolt, protruding at the center of the thermal mirror of the $\alpha$-scattering-instrument. After grasping the knob, the sensor head was lifted clear of the surface and, after a series of elevate, extend, and right azimuth commands, was positioned above point A (Figure 16).

Two 2.0-second elevate commands were executed with the sensor head held by the scoop. The motor current provided a calibration by lifting a known weight to assist in the analysis of similar data received while rock A was lifted at the same position.

The continuation of extend and left azimuth commands led to the position shown in Figure 21 , in which the target rock sample is seen at the lower-left corner of the sensor head. Continued maneuvering led to the positioning of the sensor head viewing port over this rock, as noted in Figure 16. In Figure 22 the ring around the rock shows the final position achieved.

Bearing point 12 (Figure 10) was the next site of operations; at this point, a bearing test was executed, by means of command tape 907 . A total of six 0.5 -second lower commands was executed. At the completion of the bearing test sequence, trench 5 (Figure 16) was dug; this operation required five 2.0 -second retract commands.

After the scoop was closed, extend and right

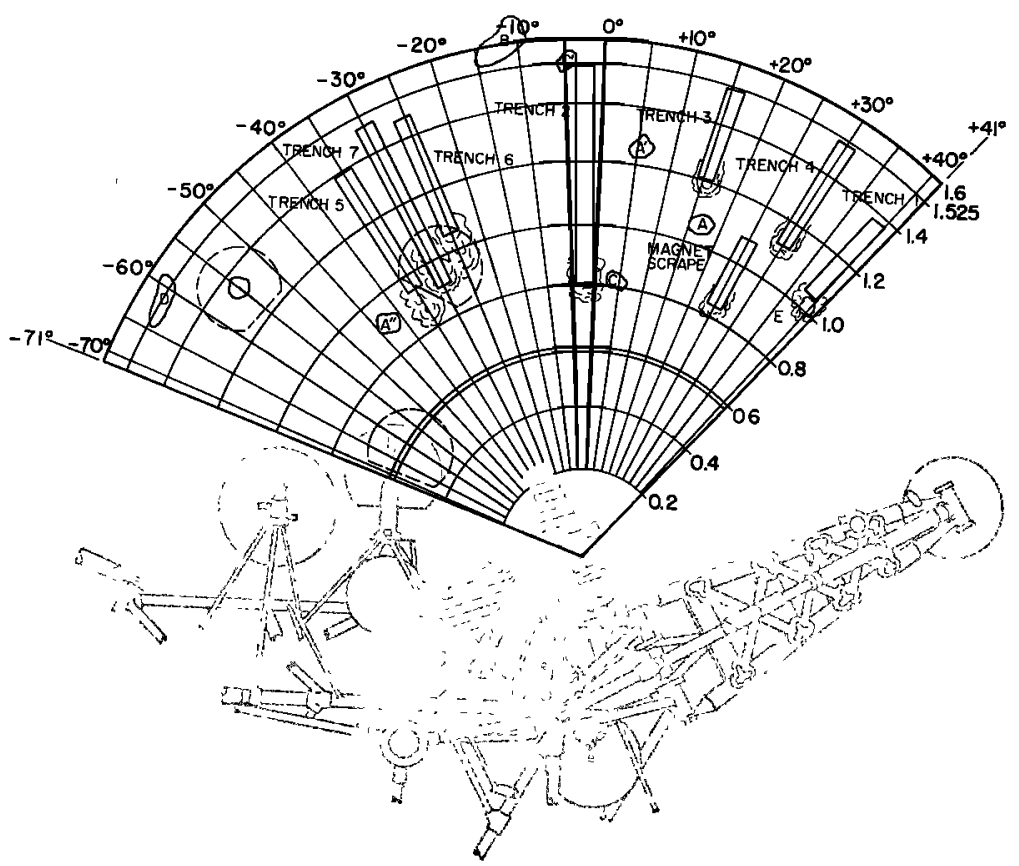

Fig. 16. Plan view of surface-sampler operations showing trenches, rocks, and the $\alpha$-scattering instrument. 


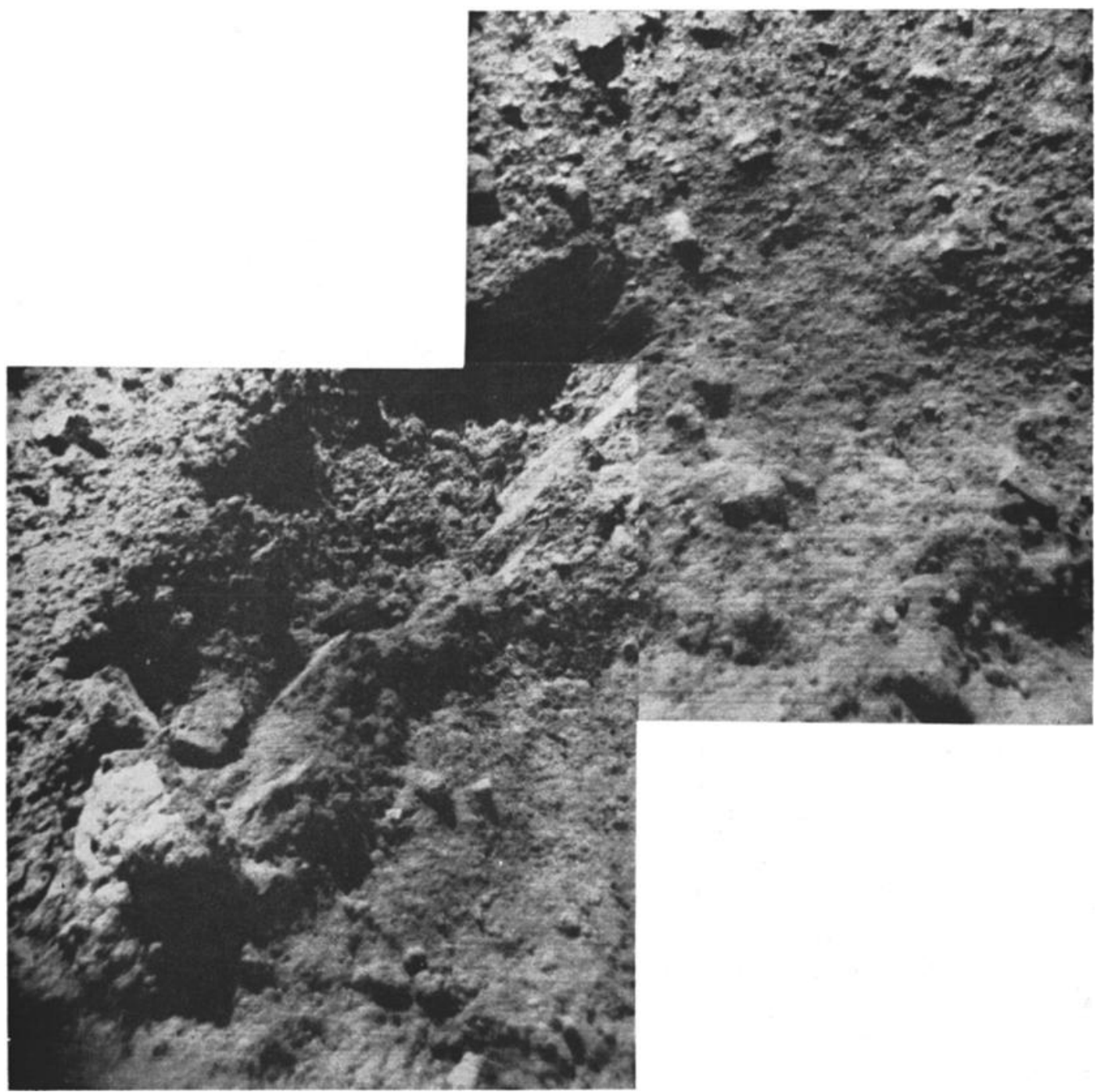

Fig. 17. Mosaic of trench 1. Note the irregular shape and shallow depth of the trench.

azimuth commands positioned the surface sampler for bearing point 13. This bearing test and trenching operation were executed in the same manner as bearing test 12 and trench 5 . Command tape 907 was used to execute five 0.5 second lower commands, followed by four 2.0second retract commands. The surface sampler remained in contact with the surface at the foot of trench 6 at the end of operations on day 021 .

Day 022. Operations started by carefully completing trench 6 , in the procedure used when the magnetic object was picked up on day 020 .
No magnetic fragments were observed at this time.

To provide a large area of disturbed subsurface material as a third sample for the $\alpha$-scattering instrument, the decision was made to dig a trench between trenches 5 and 6 . To achieve this, bearing point 14 was contacted, and a bearing test consisting of two 2.0-second lower commands was executed. The scoop was closed during this bearing test and during the subsequent retract commands, which produced trench 7 .

The debris at the foot of trenches 5,6 , and 7 


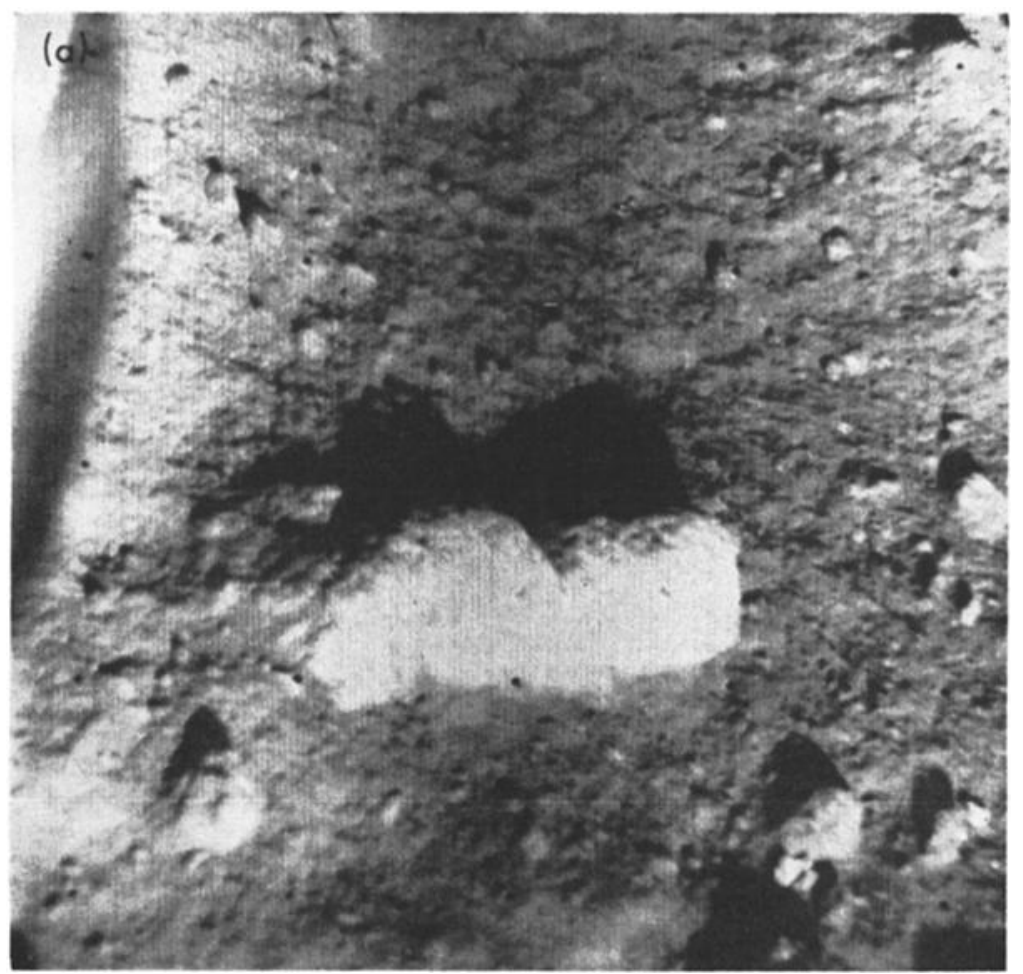

Fig. 18a. Undisturbed view, showing exposed smooth face of rock D.

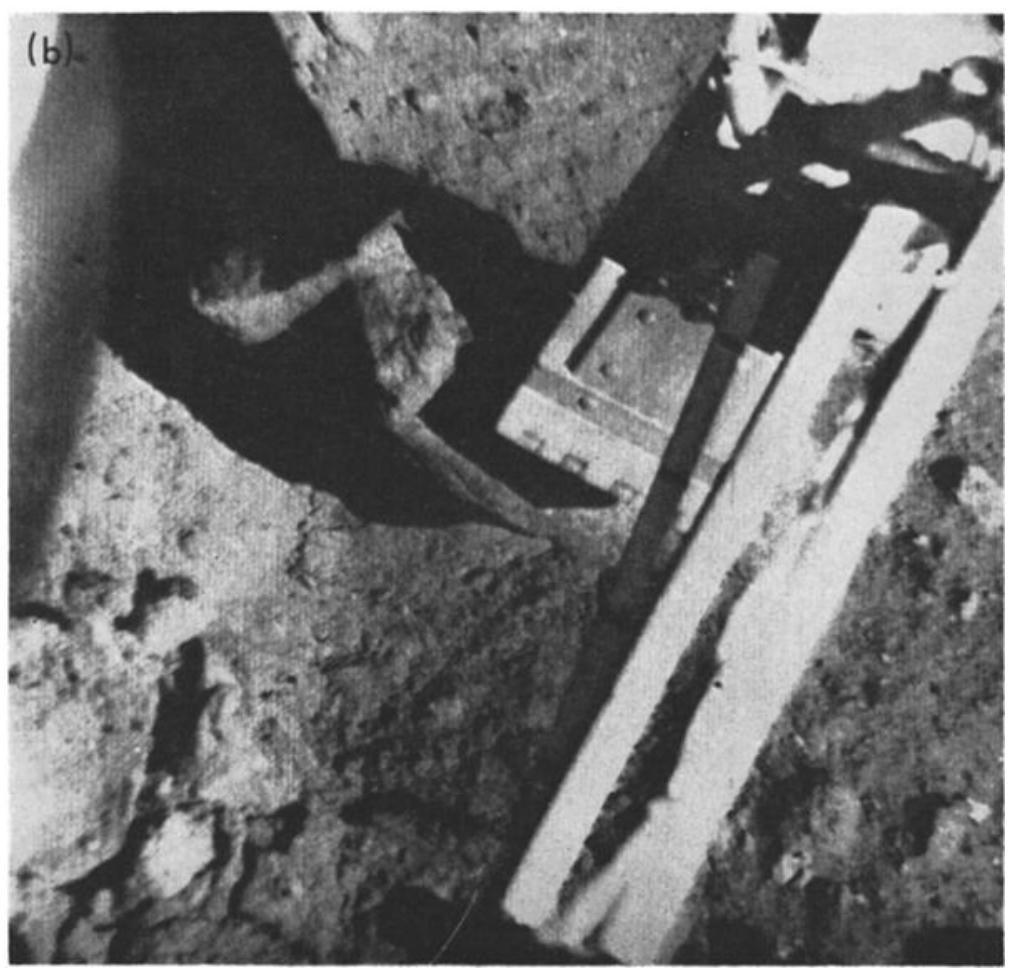

Fig. 18b. View of rock D after moving, showing angular, fragmented underside. 


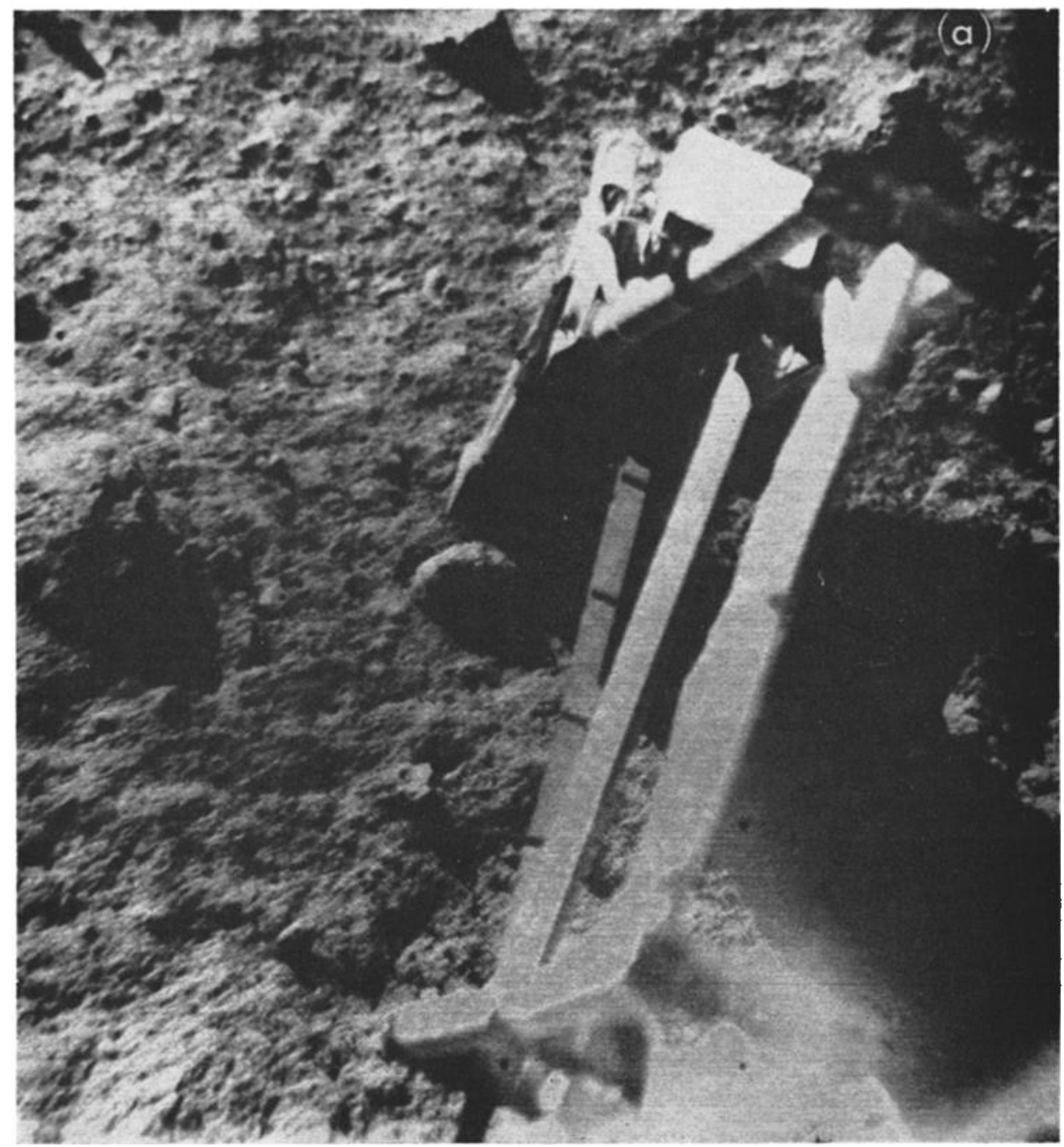

Fig. 19a. Bearing tests 8 and 9 in sequence.

provided the third sample for chemical analysis, and efforts to redeploy the sensor head to this sample followed the completion of trench 7. Redeployment again required the positioning of the scoop above the sensor head and the grasping of the knob. Figure 22 shows the sensor head after it had been lifted and moved part way to the third sample position.

The sensor head was placed on the debris at the foot of the trenches. The analysis of television pictures indicated that the viewing port was directly above trench 7 . A slight lateral movement of the sensor head was effected by placing the scoop against the side of the sensor head and commanding 0.1-second left azimuth steps. The final position is shown in Figure 16.

After positioning the sensor head on its third sample, impact tests 1 and 2 were performed. These tests consisted of positioning the scoop above the points noted in Figure 16, elevating to the desired height, and releasing the elevation drive clutch. Following the impact tests, bearing test 15 was performed, by using command tape 907 . Figures 10 and 16 show that bearing point 15 is very near trench 2 . This test was performed by taking pictures of the trench wall between each of the bearing commands in order to observe the behavior of the wall. 
Bearing test 16 made use of command tape 907, and, after each 0.5-second bearing command, the scoop was lifted clear of the surface for television coverage. Low sun angles made interior views of the bearing point difficult; after three such 0.5 -second attempts, the bearing test was completed by executing two 2.0 second commands, which resulted in a stalled condition.

By using 0.1-second right azimuth commands, the surface sampler was driven against the right azimuth stop, thus locating it above trench 1 . The scoop was opened and positioned so that the blade was above rock $\mathrm{E}$ at the foot of trench
1 (Figures 16 and 17). After two 2.0-second elevate commands, the clutch was released, and the scoop blade struck the rock. As discussed below, the rock fractured under this blow.

After careful television coverage of the fractured rock, including polarizing filter surveys, the scoop was extended and lowered into trench 2. Two 2.0 -second lower commands, followed by two 2.0-second retract commands, resulted in the surface sampler's being stalled against the subsurface rock previously encountered. The surface sampler was left in this position in anticipation of post-sunset operations.

Day 023. Sunset occurred somewhat earlier

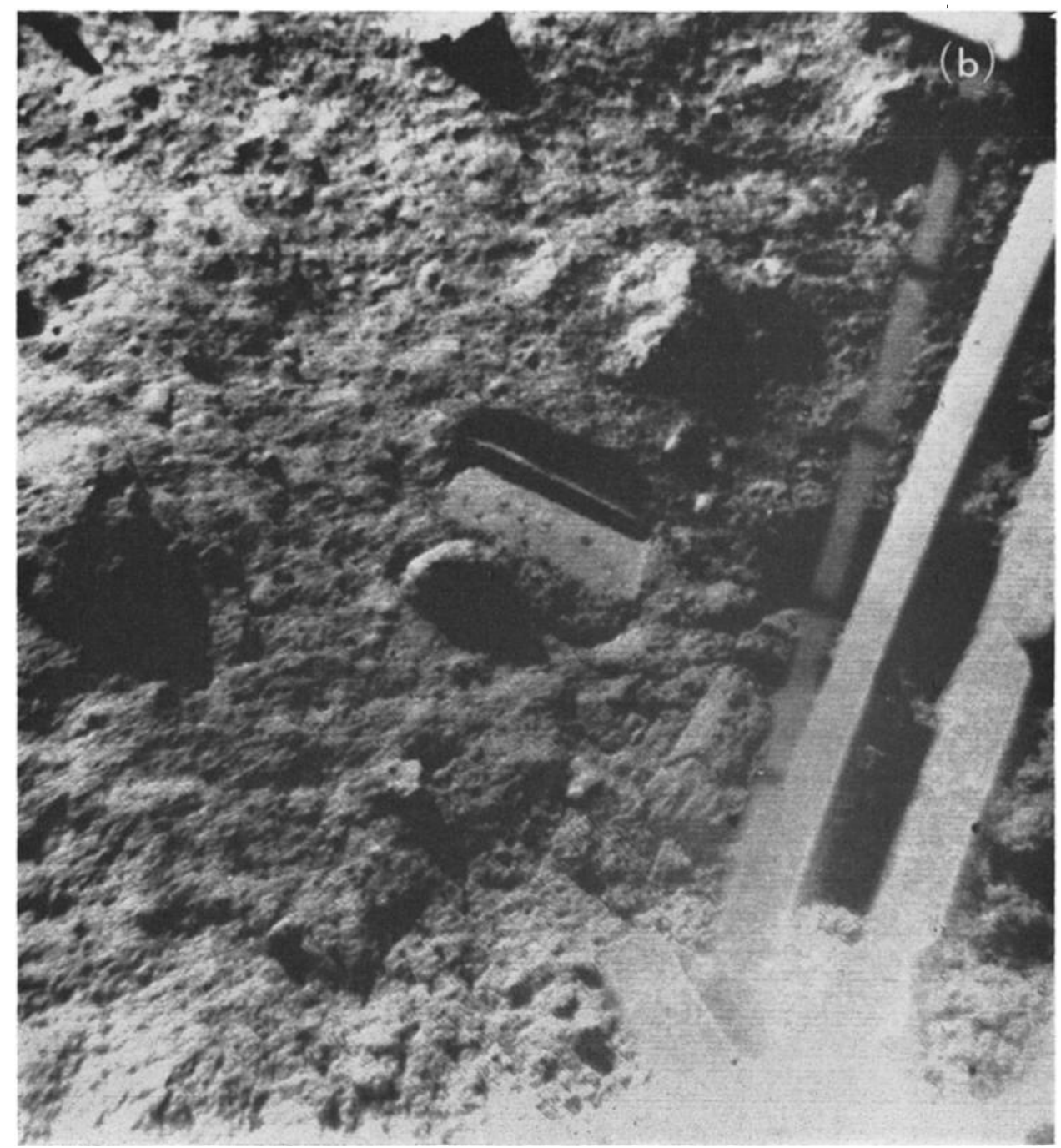

Fig. 19b. Bearing tests 8 and 9 in sequence. 


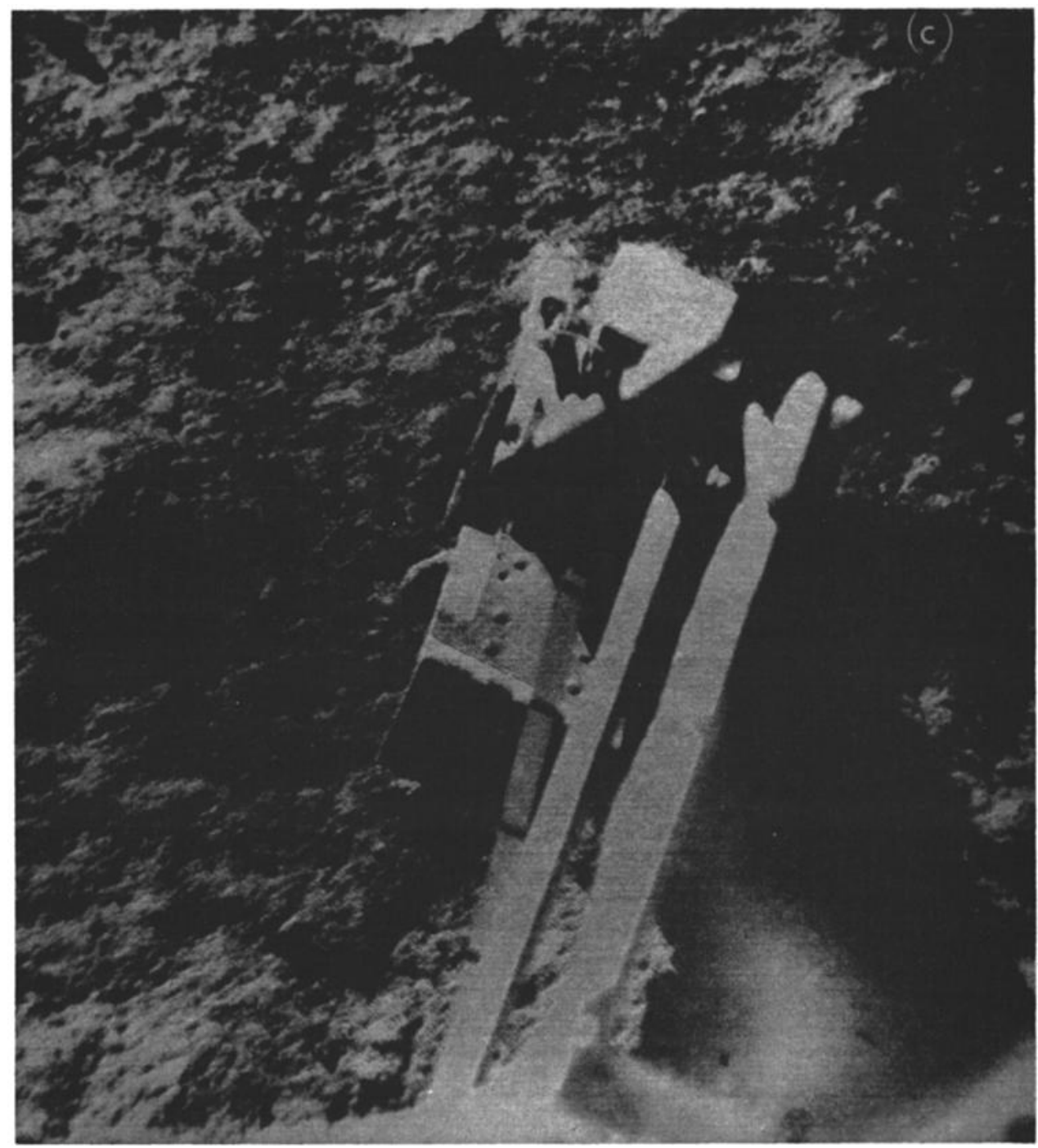

Fig. 19c. Bearing tests 8 and 9 in sequence.

than expected (because of the elevation of the western horizon), and so the decision was made to operate the surface sampler after sunset while the spacecraft was being commanded by the Deep Space Station at Robledo, Spain (DSS 61). Without benefit of television coverage, the trench 1 operation of the previous day was repeated, and the sampler again stalled against the subsurface rock. Motor current was transmitted and, at the lower motor temperature, was high, as expected.

After Goldstone, California (DSS 11), acquired spacecraft control, the surface sampler was again stalled against the rock in an attempt to dislodge it or to move the spacecraft.

\section{Lunar Operations: Second Lunar Day}

Day 045 . To verify that the surface-sumpler subsystem had survived the lunar night, a single 2.0-second extend command was executed. Both motor-current telemetry and emergency mode television verified normal response.

Day 051. Two 0.1-second extend commands verified surface-sampler performance by motorcurrent telemetry. An attempt at one elevate and two left azimuth commands (all 2.0-second 
commands) verified that the surface sampler seemed normal, but that the power system could not support operations.

\section{Discussion of Tests}

Many tests of the mechanical properties of the lunar surface were conducted by the surface sampler, in addition to other manipulatory operations. This section contains a discussion of these tests.

Description of area. Shortly after touchdown, a series of pictures was taken of the area of surface-sampler operations (see Figure 9). This narrow-angle mosaic shows the $\alpha$-scatter- ing instrument in the background position, from which it could not be successfully deployed to the surface by normal operations. There were more rocky fragments on the lunar surface in the area of Tycho than at the Surveyor 3 landing site. Some of the fragments visible in the picture are 6 to $10 \mathrm{~cm}$ across. Several of these fragments were moved during surface-sampler operations; one of them was weighed and one was broken.

Figure 23 shows the accomplishments of the surface sampler by day 021, toward the end of the first lunar day. In this mosaic, the $\alpha$-scattering instrument can be seen in its second de-

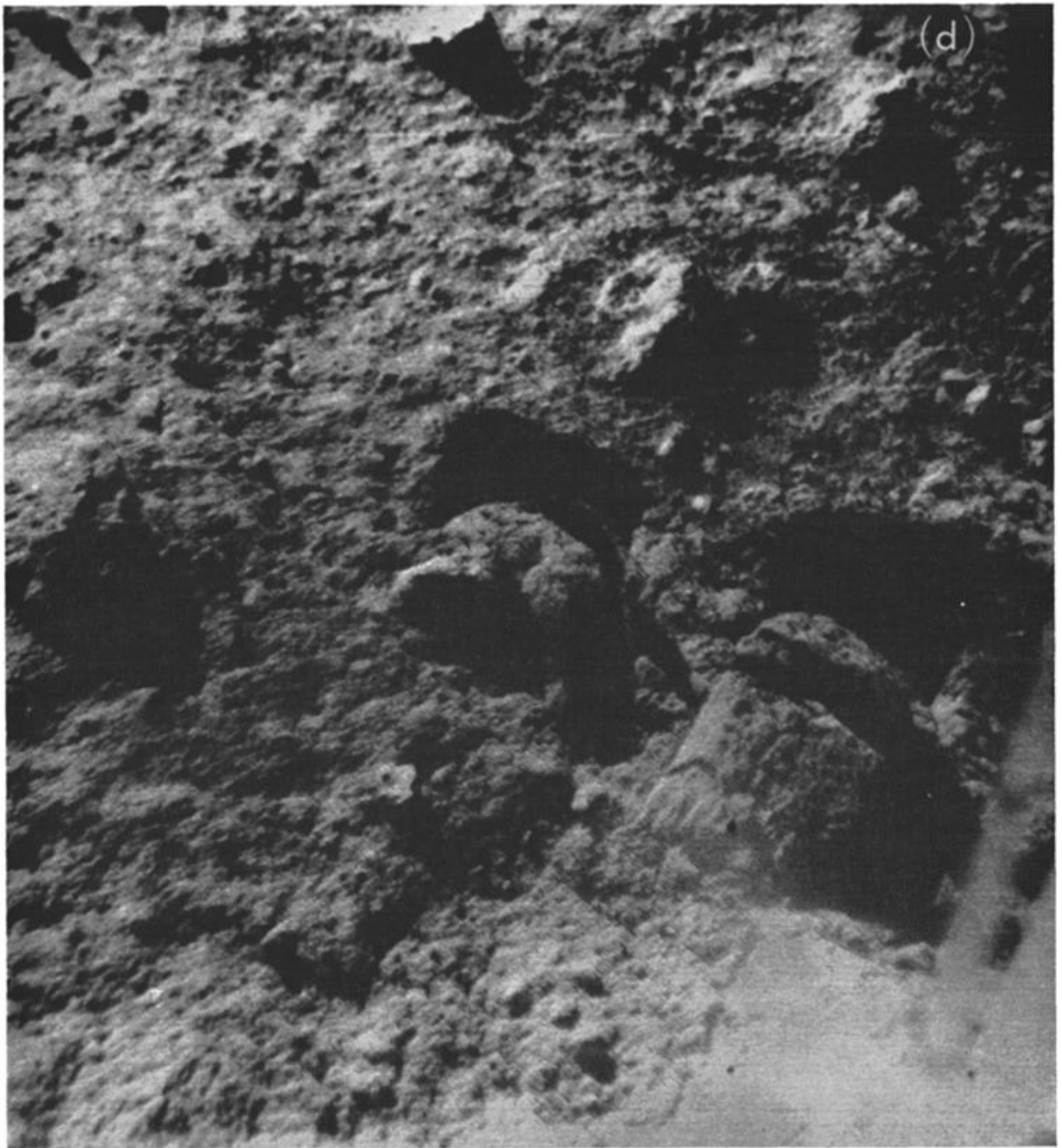

Fig. 19d. Bearing tests 8 and 9 in sequence, 


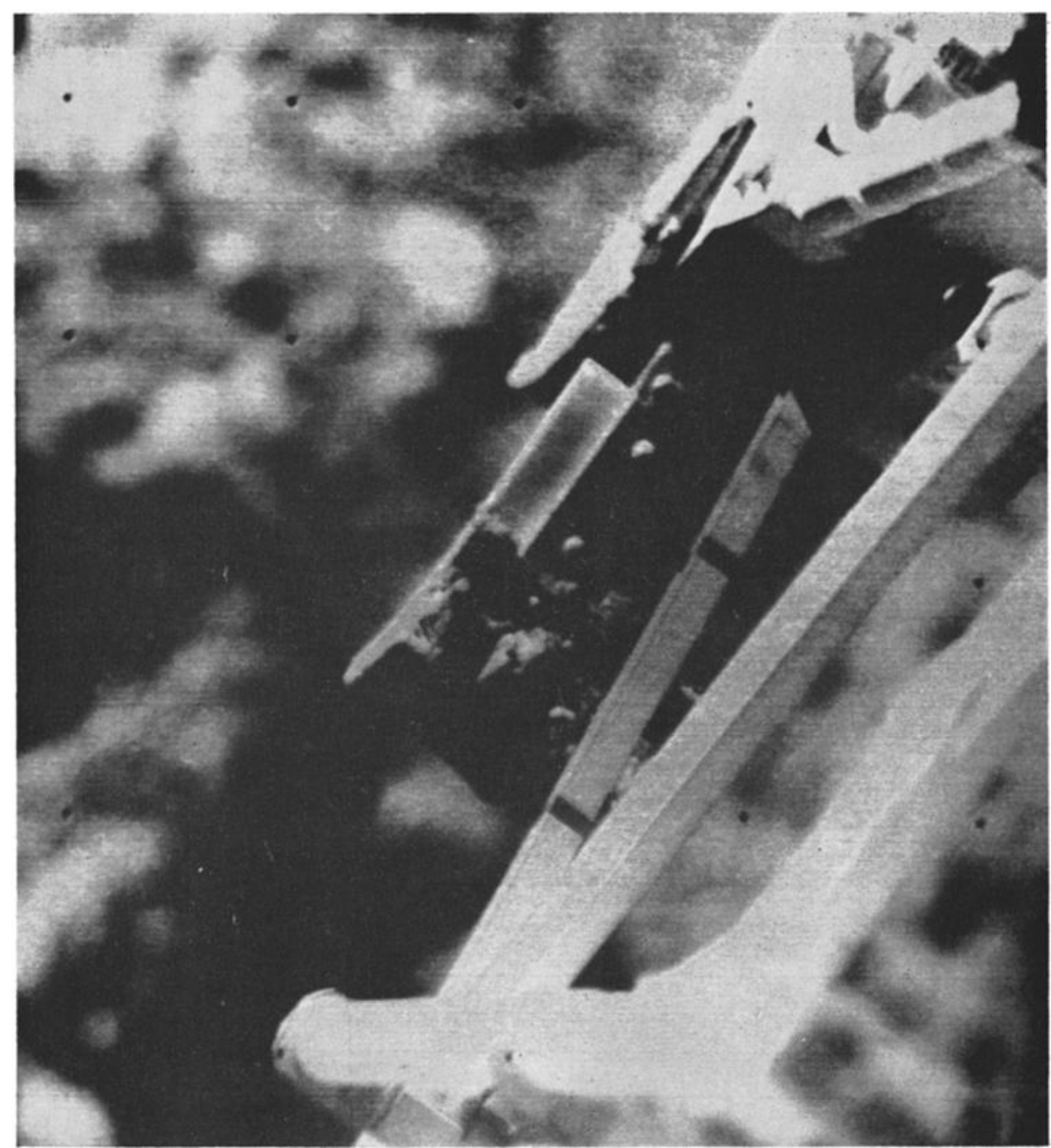

Fig. 20. Fragment adhering to surface-sampler magnets after lunar surface was contacted.

ployed position at the left-hand side of the picture; the surface sampler is in the process of excavating subsurface soil to provide the third sample for analysis. Some of the surface-sampler tests, identified in Figures 10 and 16, may also be seen in Figure 23. In particular, just to the right of the position of the surface sampler, a fairly large rock (rock B) is seen at the outer edge of the surface-sampler area. On the near side of the rock, two small trenches demonstrate that the rock was just outside the surface sampler's reach. To the right of the rock is a long, 15- to 18-cm-deep trench, identified as trench 2 in Figure 10.
Some shorter trenches are visible on the righthand side of Figure 23; on the extreme righthand edge lies a shallow trench, which was the first trench attempted. This trench could be excavated to a depth of only 2.5 to $5 \mathrm{~cm}$ because of the presence of rock immediately below the surface. At the foot of this trench is a small rock fragment (rock $E$ ), which was broken by the surface sampler into two fragments after the picture was taken. On the left-hand side of the figure, just to the right of the shadow cast by the sensor head is a somewhat rounded rock (rock A), which was weighed. Many surfacesampler operations involved this rock, which 
was finally positioned as shown in Figure 23 to permit analysis by the $\alpha$-scattering instrument. However, an undisturbed rock, better suited to analysis, was located at the position of the $\alpha^{-}$ scattering instrument in Figure 23; the instrument, as shown, is located on top of this rock. In the lower left of Figure 23, at the very edge of the sensor-head shadow, is a rounded mark or indentation in the lunar soil. This was the position of the sensor head at its first sampling site, and it was to this location that the surface sampler deployed the sensor head following its release.
Bearing tests. There were 16 bearing tests of various kinds conducted by the surface sampler before and after deployment of the $\alpha$-scattering instrument. Some of these bearing tests are described here.

Figure 24 shows a view of the result of bearing test 1 , which was performed by means of two 2.0-second down commands in which the motor current was recorded. The disturbed soil shows a remarkable resemblance to the appearance of the lunar surface at the Surveyor 3 site following the first bearing test performed at that location [Scott and Roberson, 1967]. The

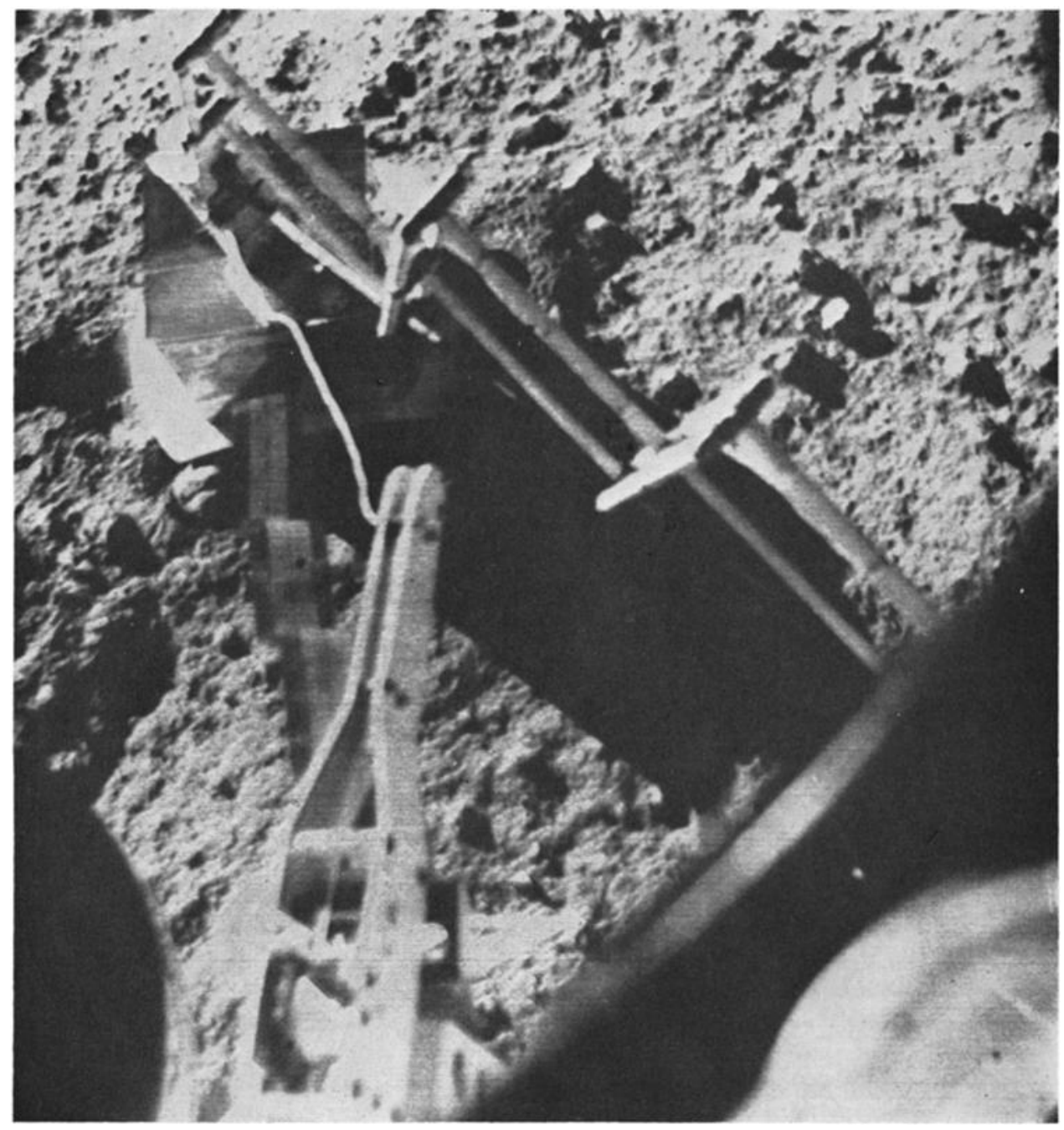

Fig. 21. Surface sampler nearing final position in deploying sensor head to second sample on the lunar surface. 


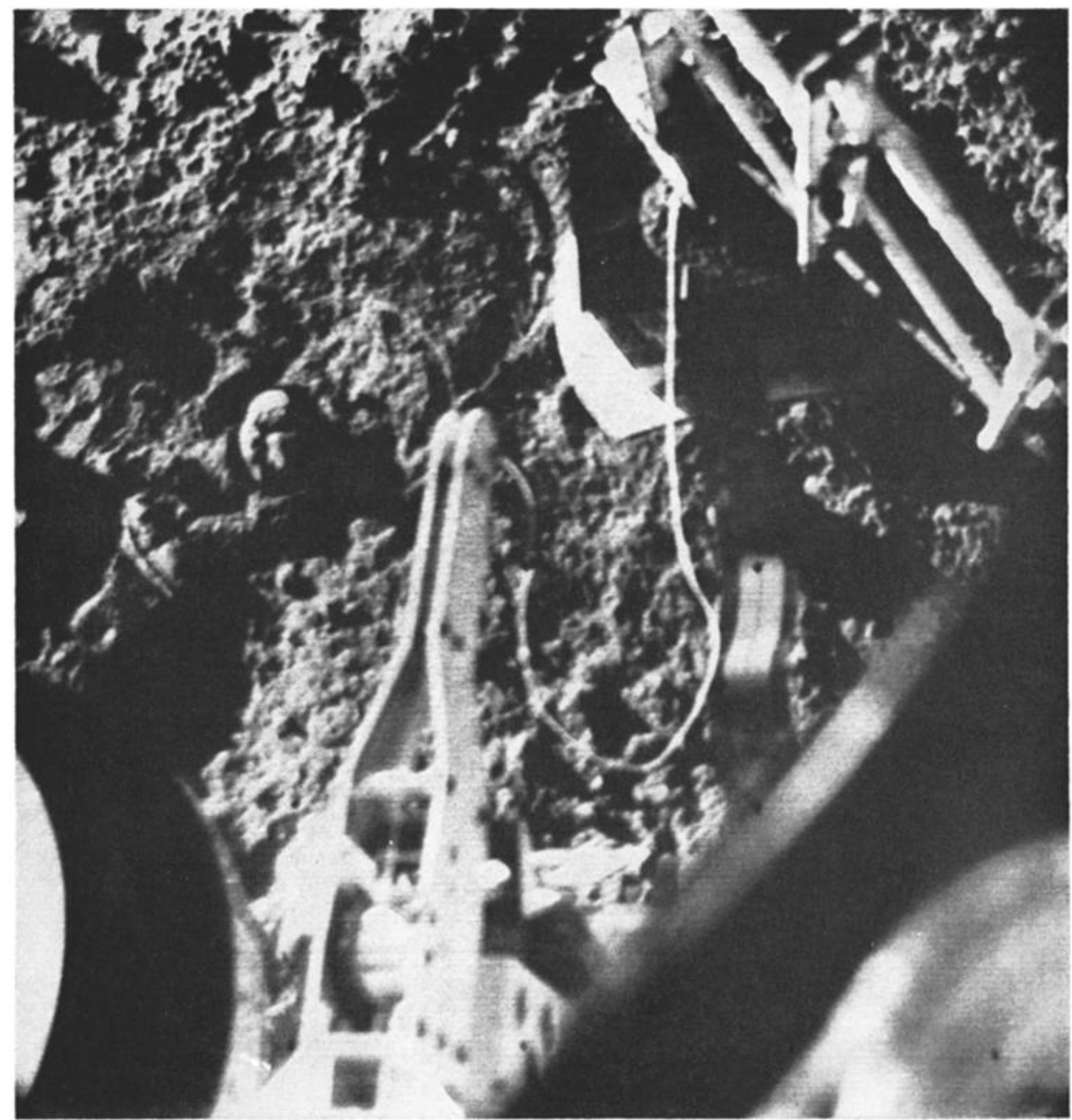

Fig. 22. Surface sampler in process of moving sensor head from second to third lunar sample. Note ring around target rock at second sample location.

total depth of penetration of the surface sampler into the lunar soil in Figure 23 was about $5 \mathrm{~cm}$ in this test. The test was apparently located on the edge of a small surface depression, which became obvious in pictures taken later in the lunar day. Consequently, the surface subjected to the test (Figure 24) slopes downward to the right, which accounts for the unsymmetrical appearance of the deformed soil. At this location, the surface sampler was at an extension distance of about $103 \mathrm{~cm}$ from the spacecraft (see Figure 23), and consequently applied its force at an angle to the surface rather than directly downward. In the disturbed lunar sur- face material, a certain amount of minor cracking appears, together with an obvious general bulging of the area.

Since bearing test 1 and the previous calibration tests of the surface sampler on the moon indicated that the sampler was in good operational condition and, in particular, that the motor currents appeared reliable, it was decided to perform a second bearing test to the left of bearing test 1 and at greater extension, using command tape 907 . Bearing test 2 was consequently performed; the appearance of this test is somewhat different from that of bearing test 1 , although some bulging of the surface material 
in the vicinity of the bearing test was also evident.

It is felt that the difference between bearing tests 1 and 2 probably results from the different angle of penetration of the surface-sampler scoop into the lunar soil; in bearing test 1 the position of the scoop tended to drag the surface material toward the spacecraft. In addition, bearing test 2 appeared to have been performed on a level surface. Once again, in Figure 12a, it can be seen that the disturbed material cracks to some extent and exhibits displacement to some distance from the point of application of the force.

Careful analysis and comparison of the pictures of the soil in the area of bearing test 2 show that it appears to have been disturbed by the bearing test to a distance of at least $9 \mathrm{~cm}$ from the near edge of the surface sampler. The maximum depth of penetration in this test was in the vicinity of $4 \mathrm{~cm}$. A preliminary analysis of force-versus-penetration data from bearing test 2 has been made from the motor-current data and pictures; the force-versus-penetration relationship is shown in Figure 4.

Another test (bearing test 4), also made with command tape 907 and exhibiting a somewhat similar appearance to bearing test 2 , is shown after completion in Figure 12b. Once again, in this test, a depth of penetration of about $2 \mathrm{~cm}$ was attained, and the soil was disturbed to a distance of approximately $8 \mathrm{~cm}$ from the near edge of the surface sampler. In this test, a piece of rock (or a rock fragment) seems to have been encountered near the surface at the lefthand top corner of the surface-sampler impression (Figure 12b), since there is some soil cracking, and the surface appears somewhat bulged beyond the surface-sampler impression. It appears that the surface sampler may have pressed down on one corner of the rock fragment that was slightly below the surface, and that this fragment tilted upward, thereby cracking the surface.

Bearing test 5 is shown in Figure 12c; bearing test 6 , conducted with an open scoop, is shown in Figure 12d. In bearing test 5 , only a relatively minor amount of surface disturbance in the vicinity of the surface-sampler scoop tip appears obvious, although some displacement of the surface and some bulging have occurred. The amount of penetration in this test was about $1 \mathrm{~cm}$, which is considerably less than on the previous tests. Bearing test 6 was performed with the scoop door open; the test shows that the scoop at maximum force has penetrated a distance of about 6 to $7 \mathrm{~cm}$ into the soil.

Because there are indications that somewhat different surface disturbances and penetrations

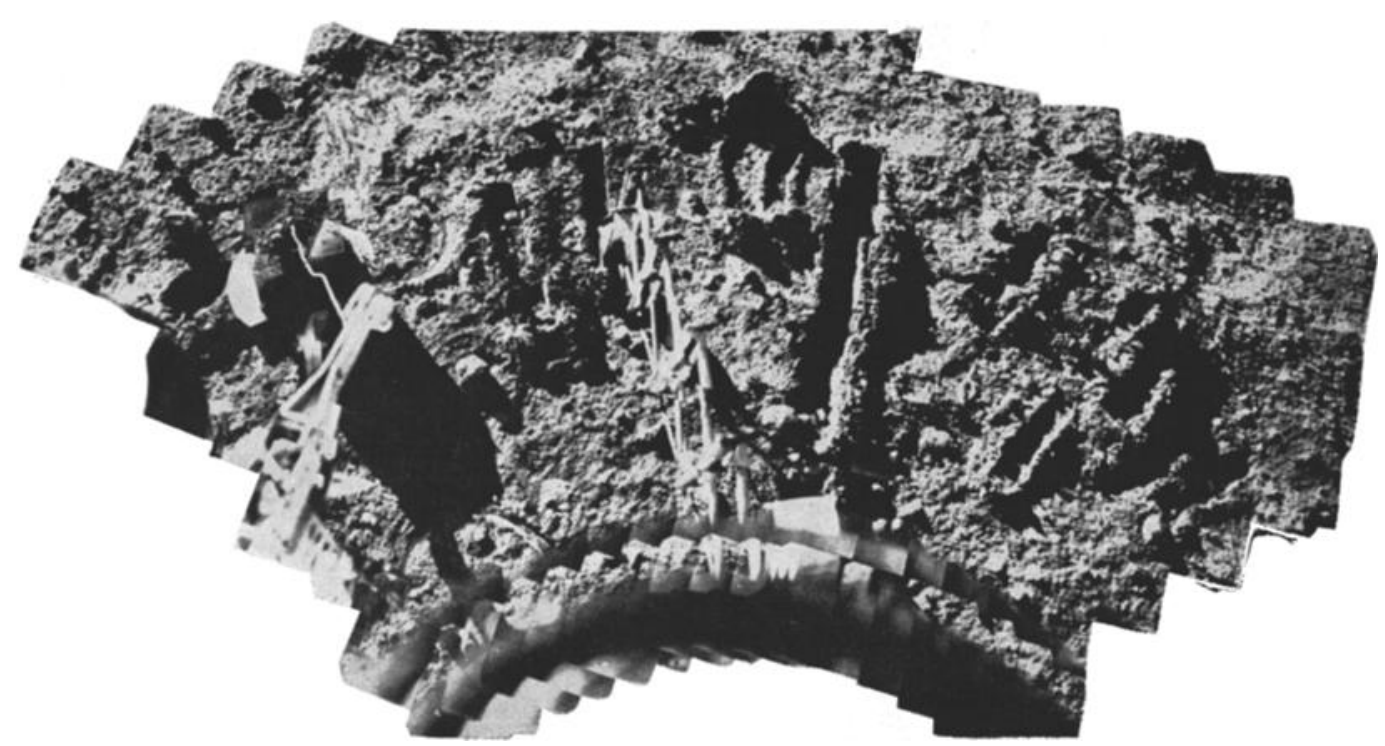

Fig. 23. Mosaic of area of operations. 


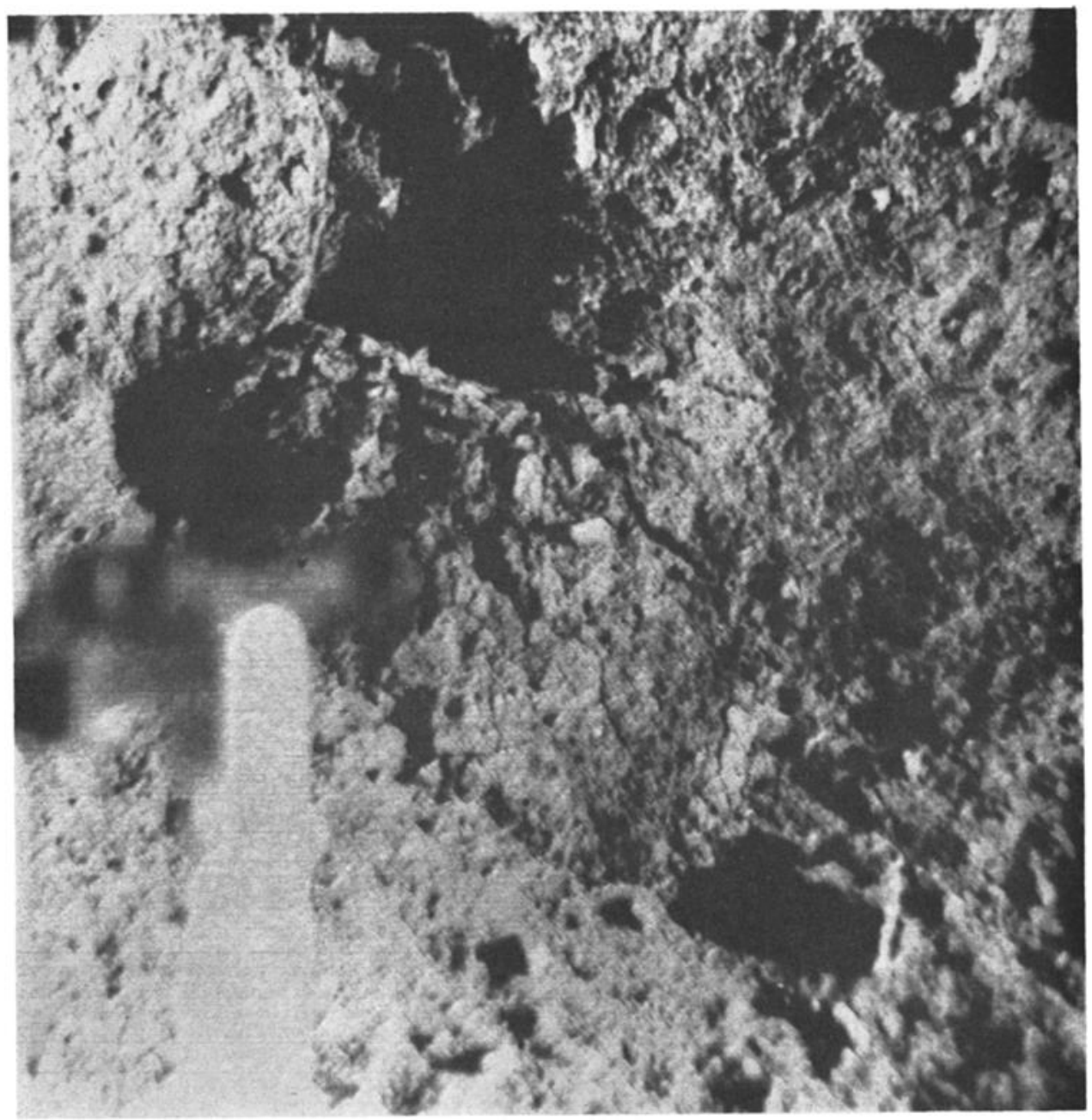

Fig. 24. Results of bearing test 1 .

were being obtained from test to test during Surveyor 7 surface-sampler operations, two special tests were performed to study this effect (see Figure 19). Figure 19a shows bearing test 8 , which resulted in an extremely small amount of penetration into the surface. In this test, the far edge of the surface-sampler scoop penetrated perhaps $1 \mathrm{~cm}$, whereas the near edge of the scoop penetrated approximately $0.5 \mathrm{~cm}$, and extremely little surface disturbance was manifested on the near side of the scoop. The impression left by the surface sampler is smooth and distinct (Figure 19b), and the various features of the scoop tip can be seen clearly. Because of the possibility that in this test the penetration was limited by an underlying rock, it was decided to open the scoop and perform another bearing test in precisely the same location. Figure $19 c$ shows the result of driving the open scoop down into the surface. This was bearing test 9 , and it can be seen that the scoop has penetrated a distance of 5 to $8 \mathrm{~cm}$ without causing any marked surface disturbance, which would indicate the presence of an underlying rock.

In Figure $19 d$, the lunar surface is shown in the vicinity of bearing tests 8 and 9 following the removal of the scoop from the surface; it can be seen that only a minimal amount of surface disturbance has occurred. The right-hand 
side of Figure $19 d$ shows the surface at bearing test 7 , which was a test performed with the scoop full of soil from trench 2. The mass of soil, which appears on the spacecraft side of that test mark in Figure $19 d$, is, in fact, material that had been compressed in the scoop, but remained on the surface (still retaining the shape of the inside of the scoop) after the surface sampler had been withdrawn.

Bearing test 13, which was performed with the scoop closed, is shown in Figure 25a; one retract command was given after the maximum downward force on the scoop in the bearing test had been obtained (Figure 25b). It is seen that, as a result of dragging the scoop backward, the penetration of the scoop into the lunar soil has been greatly increased because of the additional shearing stresses applied to the surface.

Trenching operations. Trenching operations during the Surveyor 7 mission were made for a variety of purposes. The first trench (Figure 16) was dug at the extreme right-hand end of the surface-sampler operations area. This area was selected because it was possible to bring the surface sampler to the extreme right-hand stop very readily after moving it away from the

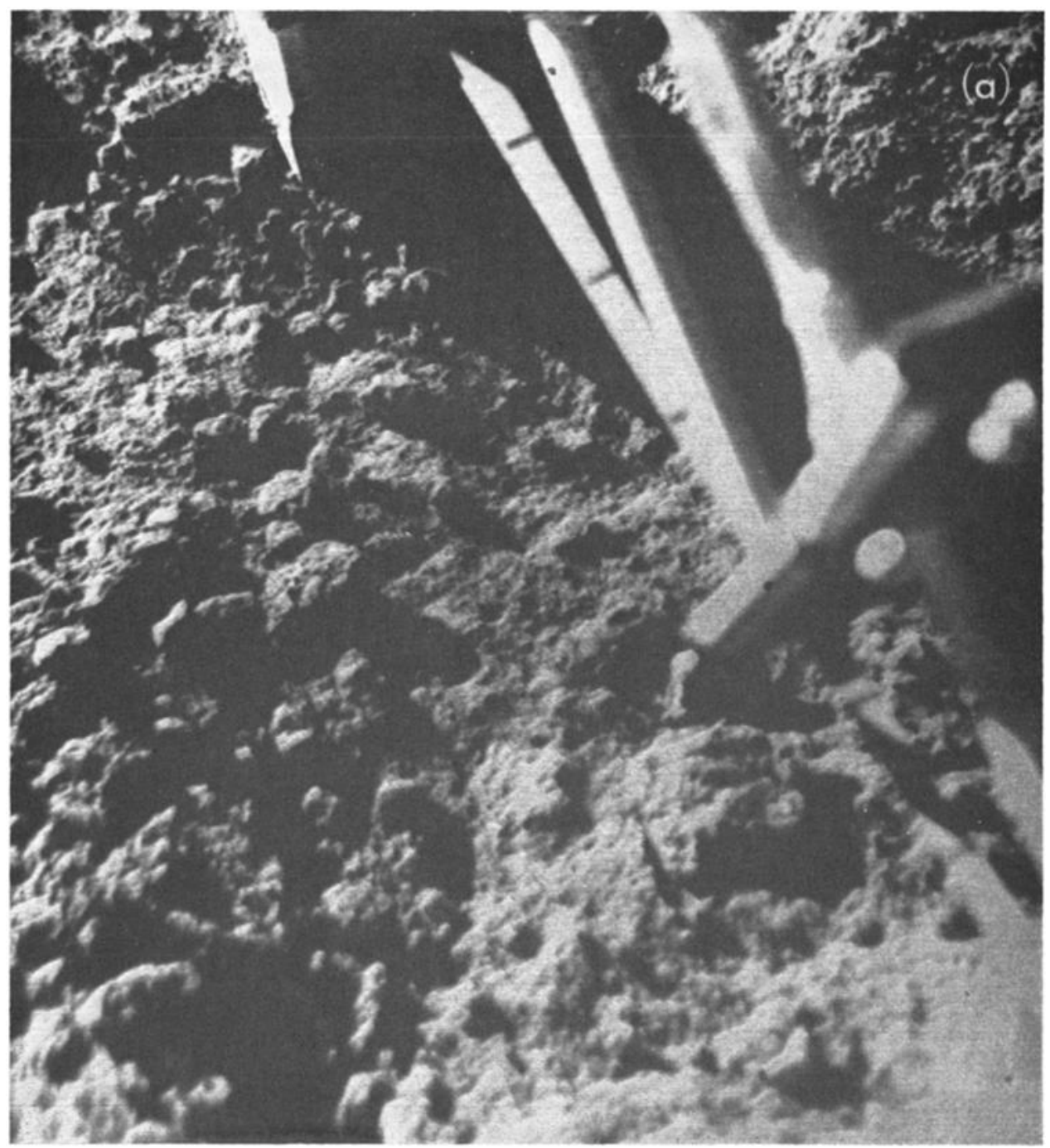

Fig. 25a. Bearing test 13. 


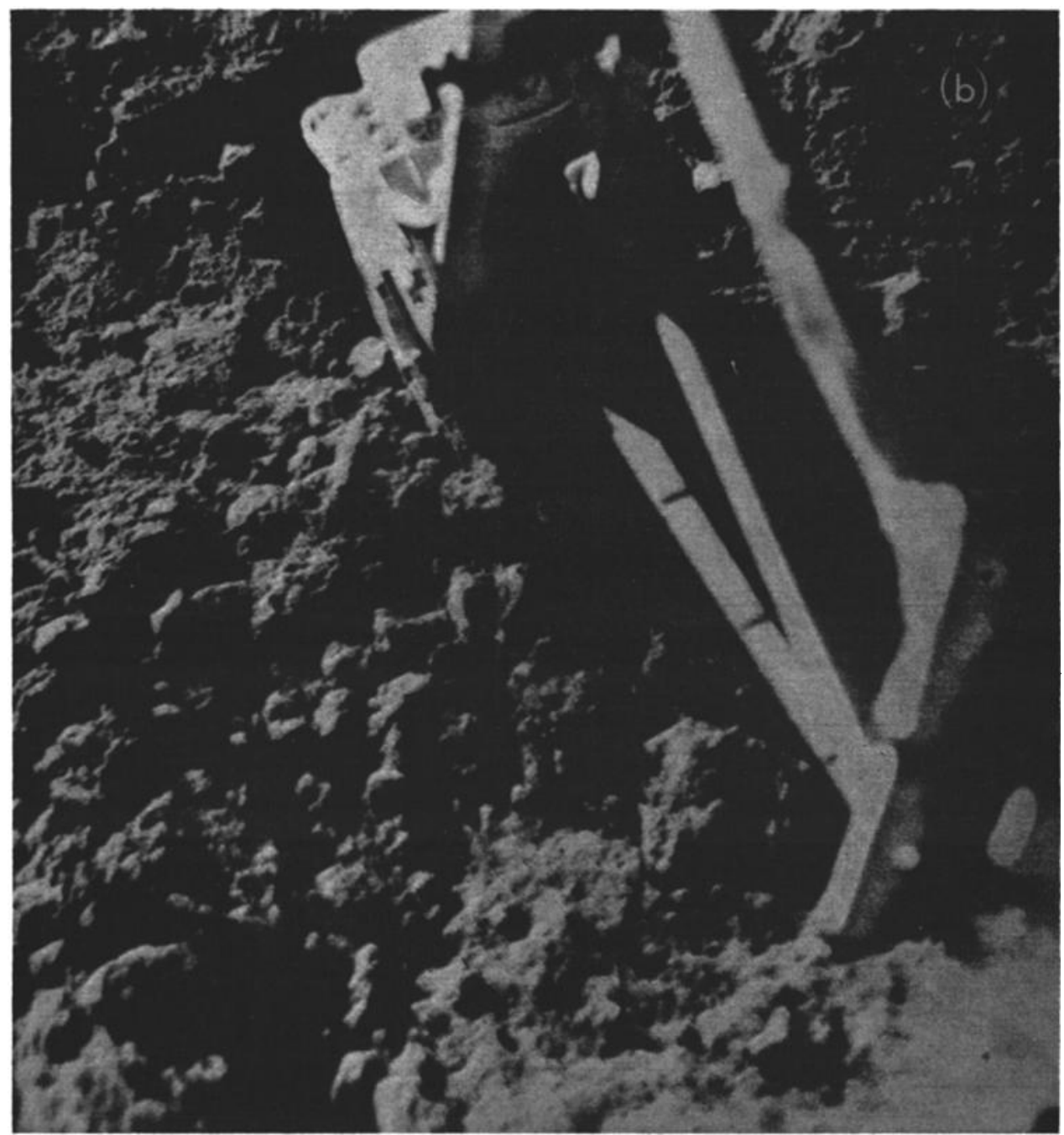

Fig. 25b. Trench 6, performed in sequence at the sample point.

trench. When trenching was attempted at this position, however, it was found that rock material (or a large rock) lay under the trench, at a depth of only about $2.5 \mathrm{~cm}$, so that deeper penetrations could not be obtained. The rock had an irregular upper surface, and subsequent drag tests with the simultaneous recording of retraction motor current indicated fluctuations in current as the surface sampler rode over the underlying rock material.

Shortly after sunset of the first lunar day, the surface sampler, which had been left in a stalled position on the rock underlying the near end of trench 1 , was operated in the retraction mode again at a motor temperature of about $-167^{\circ} \mathrm{F}$ in order to exert a very large retraction force on the rock. No movement of the rock was apparent in the pictures taken, although some deflection of the leg 2 shock absorber was achieved. Considering the retraction force of 1.8 to $2.0 \times$ $10^{7}$ dynes that can be generated at very low motor temperatures, it would seem that the rock must have been a substantial fragment. Trench 1 is shown in Figure 17.

Following deployment of the sensor head of the $\alpha$-scattering-instrument, another trench was attempted in approximately the middle of the surface-sampler operations area (see Figure 16). 

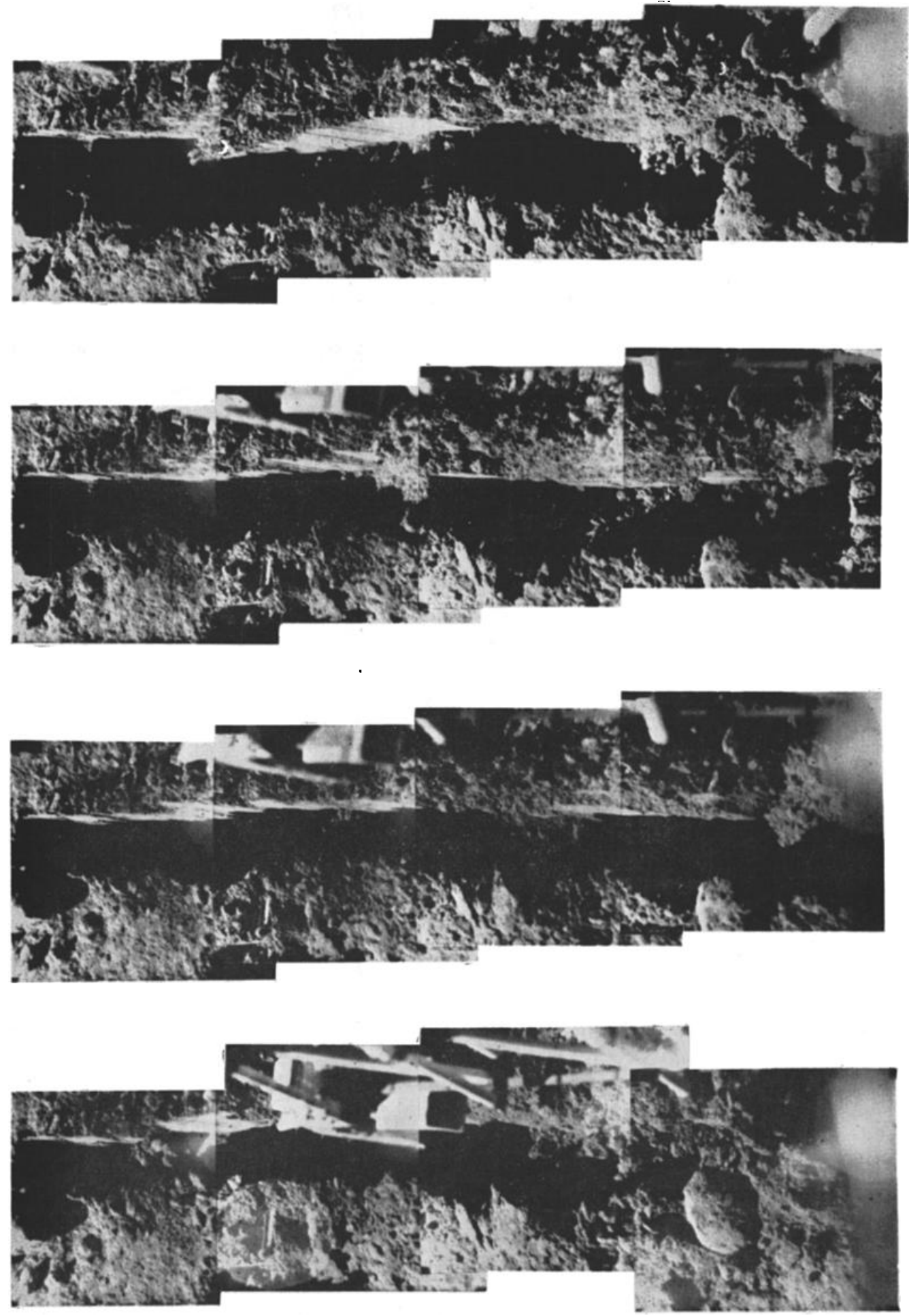

: 


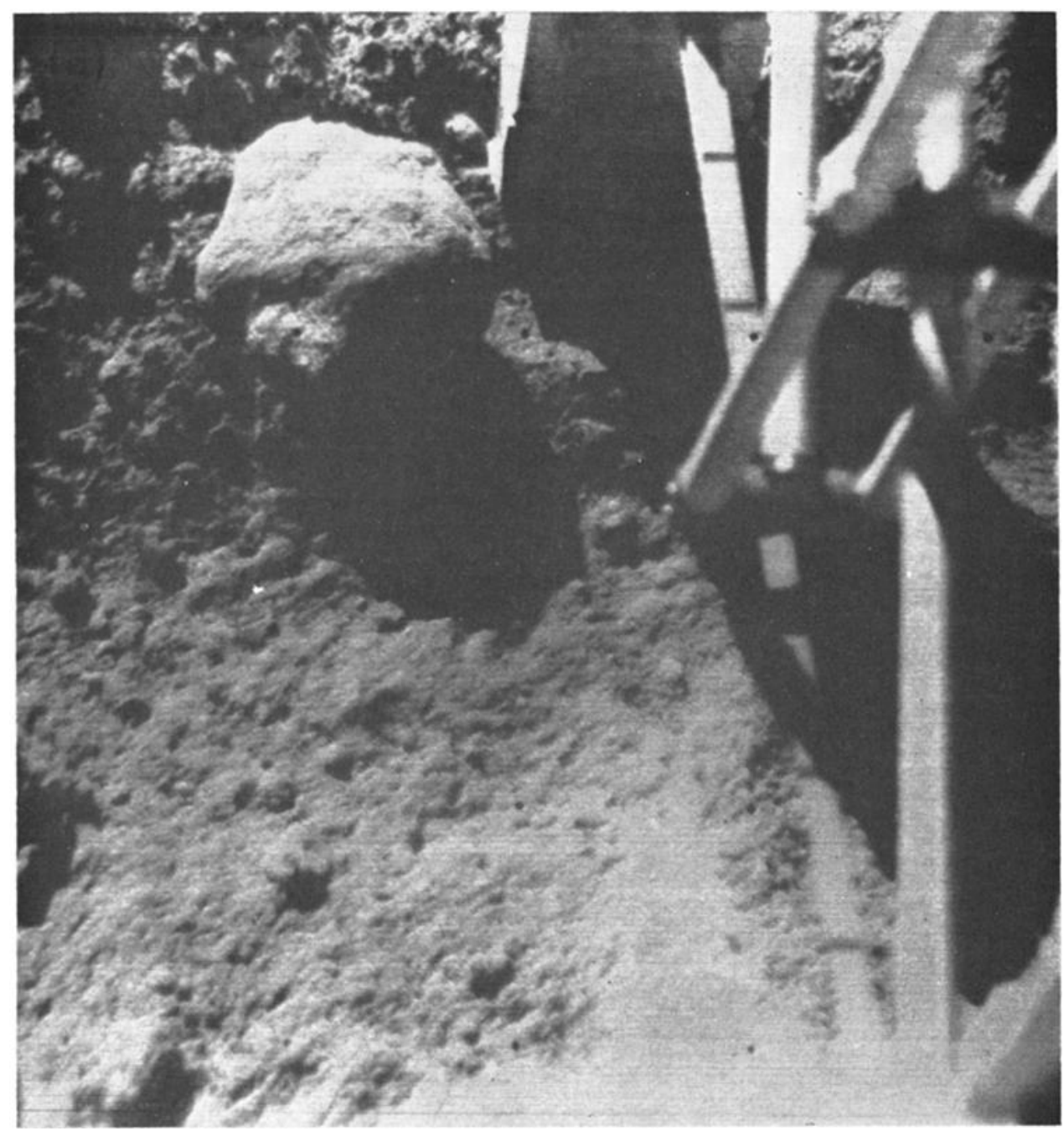

Fig. 27a. Direct view of rock A after it was moved.

Several trenching passes were made through this trench, which was eventually enlarged to a length of approximately $75 \mathrm{~cm}$, a depth of about $15 \mathrm{~cm}$, and a width of $5 \mathrm{~cm}$. Two obstructions were observed in this trench, one at the head of the trench, where the surface sampler was deflected to the left around some subsurface object, and one approximately two-thirds of the way down the trench toward the spacecraft, where a small protuberance again interrupted surface-sampler operations. The retraction motor stalled on the object, which could not be extracted from the surface, and was thereupon avoided in trenching operations. The appear- ance of trench 2 at several stages in its construction is shown in Figure 26. In depth and general appearance, the trench is not dissimilar to trenches excavated by the surface sampler on Surveyor 3 [Scott and Roberson, 1967].

Three trenching operations were performed at the left side of the surface-sampler area in order to provide subsurface materials for the third sample to be analyzed by the $\alpha$-scattering instrument. The sensor head was subsequently positioned in this area. Other trenches were dug with the scoop closed (see Figures $25 a$ and $25 b$ ) in order to examine the change in the amount of penetration of the surface sampler by apply- 
ing lateral shearing stresses after a drag test; a short trench was made for the purpose of locating a possible fragment on the surface.

Rock weighing. Early on the first lunar day, a rock (rock A) was observed that was in a position convenient for the surface sampler to reach, and that was of suitable dimensions to be enclosed in the surface-sampler scoop. This rock was moved on a number of occasions to present its various surfaces to the camera for observation and to provide a possible alternate rock for chemical analysis. In the course of picking up the rock, the motor current required to elevate the surface sampler, both with and without the rock, was measured. On one occasion, the rock was picked up in the surface-sampler scoop; a pair of pictures was taken, both directly and indirectly through the auxiliary mirror on the spacecraft mast, to provide stereoscopic imagery; the rock was dropped and another pair of stereo pictures was taken. From these pictures, the deflection of the surface sampler can be measured so that, with the known force-deflection relationship of the surface sampler, the weight of the rock can be obtained. From the stereo pairs of pictures taken, the size of the rock can be measured, and the density of the rock can be calculated. At present, the volume

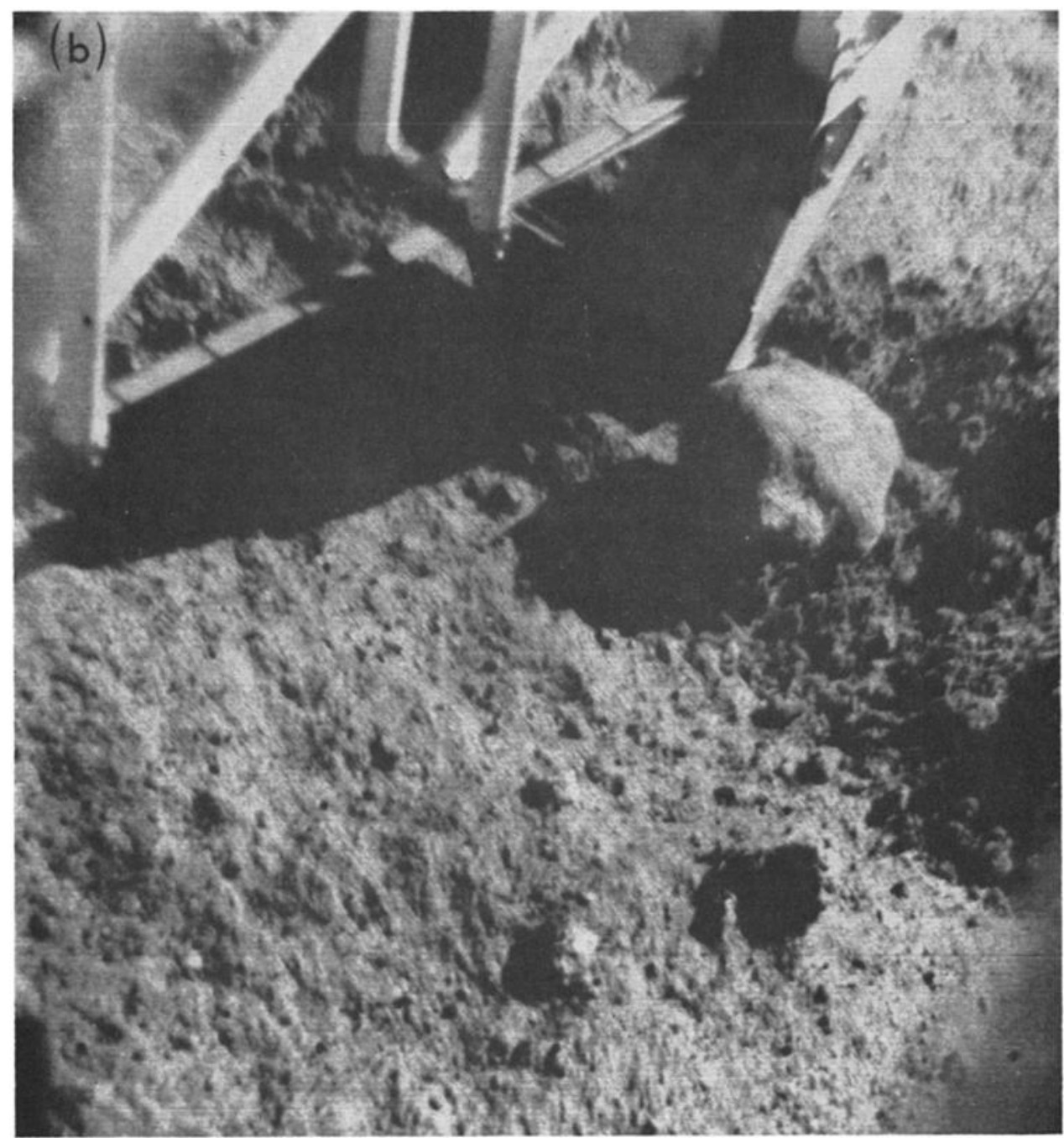

Fig. 27b. View through the stereo mirror. Rock $\mathbf{A}$ after it was moved. 


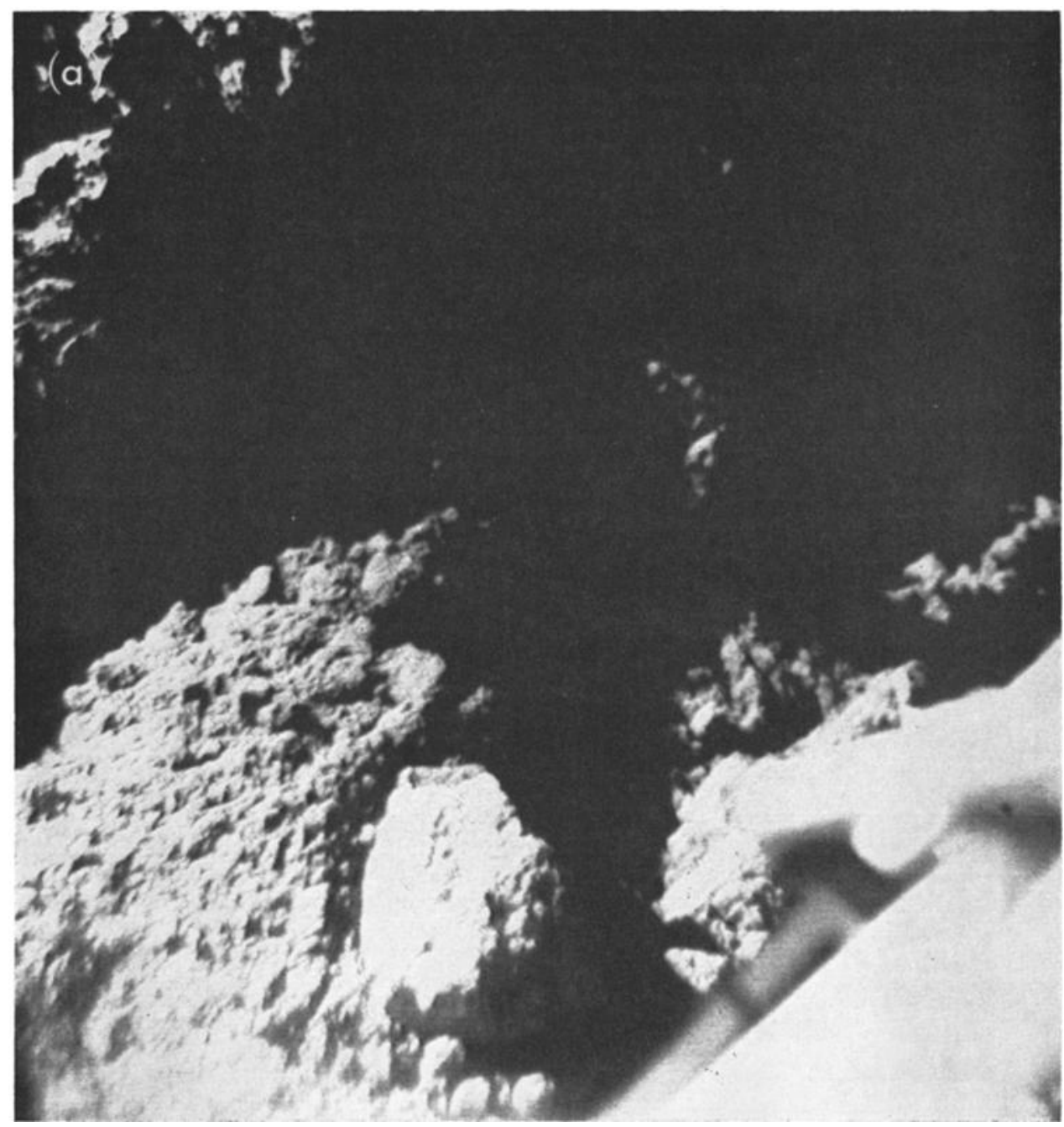

Fig. 28a. Rock $\mathrm{E}$ before breaking.

of the rock has only been estimated from its over-all dimensions; its density will be discussed in a following section. The pictures of rock $\mathrm{A}$ used in the measurements are shown in Figures $27 a$ and $27 b$.

An attempt was made to pick up another rock (rock C), but it apparently was flipped out of the jaws of the surface sampler by the coil spring in the scoop door, and it landed at the extreme edge of the surface-sampler operations area. A third rock (rock D); which appears at the extreme left edge of the area, had a rounded protuberance above the surface (see Figure 18a). This rock was of such dimensions that an attempt was made to pick it up also. The rock, on excavation, revealed a substantial surface underlying the soil of a much more angular appearance than the surface projection, indicating that an erosion process had occurred on the exposed part of the rock (Figure 18b). Unfortunately, this rock was slightly too large for the surface sampler to grasp and consequently coíld not be picked up. The attempt to weigh it was abandoned because of the timeconsuming nature of the effort required.

Because of the presence of polarizing filters on the Surveyor 7 television camera, it was considered of value to attempt to break one of the 
lunar rocks so that a polarizing sequence of pictures could be taken on any fresh surface that might be revealed. For this purpose, another rock (rock E), lying at the foot of trench 1 , was selected because of the suitable viewing angle and the nearness of the rock for pictures. Figure $28 a$ is a picture of rock $E$ before it was broken by the surface sampler. After the open scoop was located appropriately on the rock's surface, the surface sampler was elevated to a height of about 35 to $40 \mathrm{~cm}$ above the rock and the clutch was operated. After the impact, the rock had moved slightly toward the spacecraft, and a fragment of the rock had been broken off (Figures $28 b$ and 28c); Figure 28c affords a slightly better view of the broken fragment. After this operation, a polarimetric study of the rock was made.

Other operations. When the sensor head of the $\alpha$-scattering instrument was being moved to its second location, a certain amount of soil that had adhered to the surface-sampler scoop was dropped on top of the mirror surface, giving it the appearance shown in Figure 29a. When the sensor head had been in its second sampling position for approximately 24 hours, it was moved by the surface sampler to its third location. The sequence of operations involved first

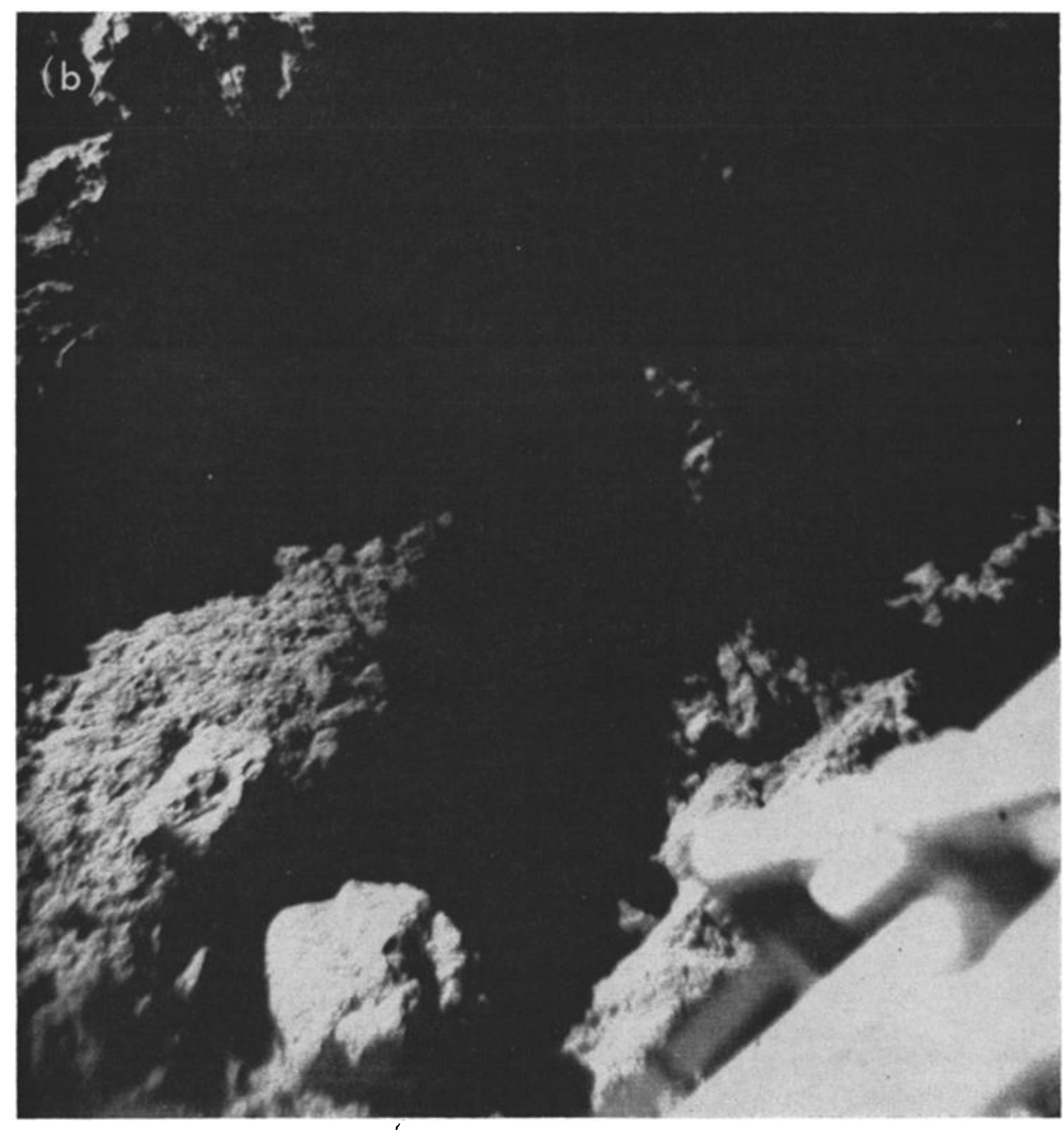

Fig. 28b. Rock E after breaking. 


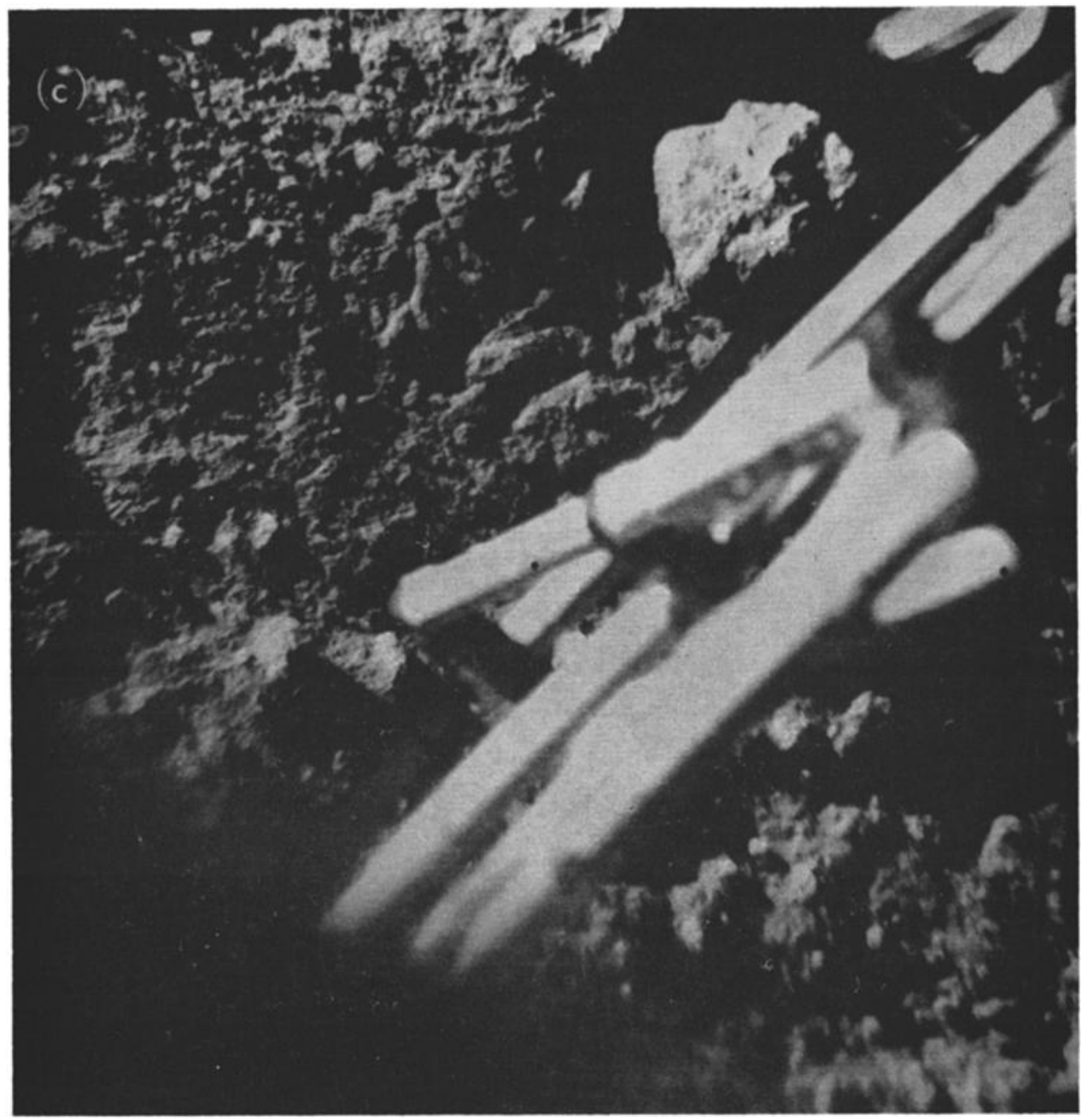

Fig. 25a. Bearing test 13.

picking up the sensor head and then making a series of movements to the right in 0.1 -second steps. This type of motion is quite jerky, and the appearance of the sensor head after two of these right steps is shown in Figure $29 b$. It can be seen that some of the soil on the $\alpha$-scattering instrument has slid to one side during the motion, leaving a fairly clean surface with only a fine coating of dust. Since the mirror surface is made of Vycor glass, a comparison of Figures $29 a$ and $29 b$ would seem to indicate that, over a 24-hour period, strong adherence of the lunar surface material to the surface of the mirror did not develop.
Careful photographic studies were made of the two small horseshoe magnets, located in the base of the scoop door, both before lunar surface operations and at various times during the first lunar day. The magnets apparently picked up a coating of magnetic material from the lunar surface. In addition, the surface sampler was dragged through the surface at a selected location in order to determine if a small fragment of lunar surface had magnetic characteristics. A fragment was, in fact, found adhering to the surface sampler, which was elevated for better inspection of the fragment (see Figure $20)$. 


\section{Preliminary Analyses and Results}

Soil properties. In general, it appears that the bearing tests performed from Surveyor 7 exerted forces on the lunar surface similar in magnitude to those of the tests performed during the Surveyor 3 mission, although the retraction forces on Surveyor 7 were considerably larger than those on Surveyor 3. However, the consequences to the lunar surface varied considerably from place to place as can be seen in Figures 12, 19, and 24. It appeared from the trenching tests that a varying depth of lunar soil ranging from perhaps 1 to at least $15 \mathrm{~cm}$ existed over the operational area of the surface sampler at the Surveyor 7 site, in contrast to a relatively uniform depth of material within the capabilities of the surface sampler at the Surveyor 3 site. Consequently, the variation in behavior of the bearing tests may have been caused by a varying depth of lunar material over underlying rocks or a rock surface. In general, however, the material behavior was not substantially different from that exhibited in the Surveyor 3 surface-sampler operations; as a first estimate, it is considered that essentially the same density, friction, and cohesion values can be considered representative of the soil in the Tycho area.

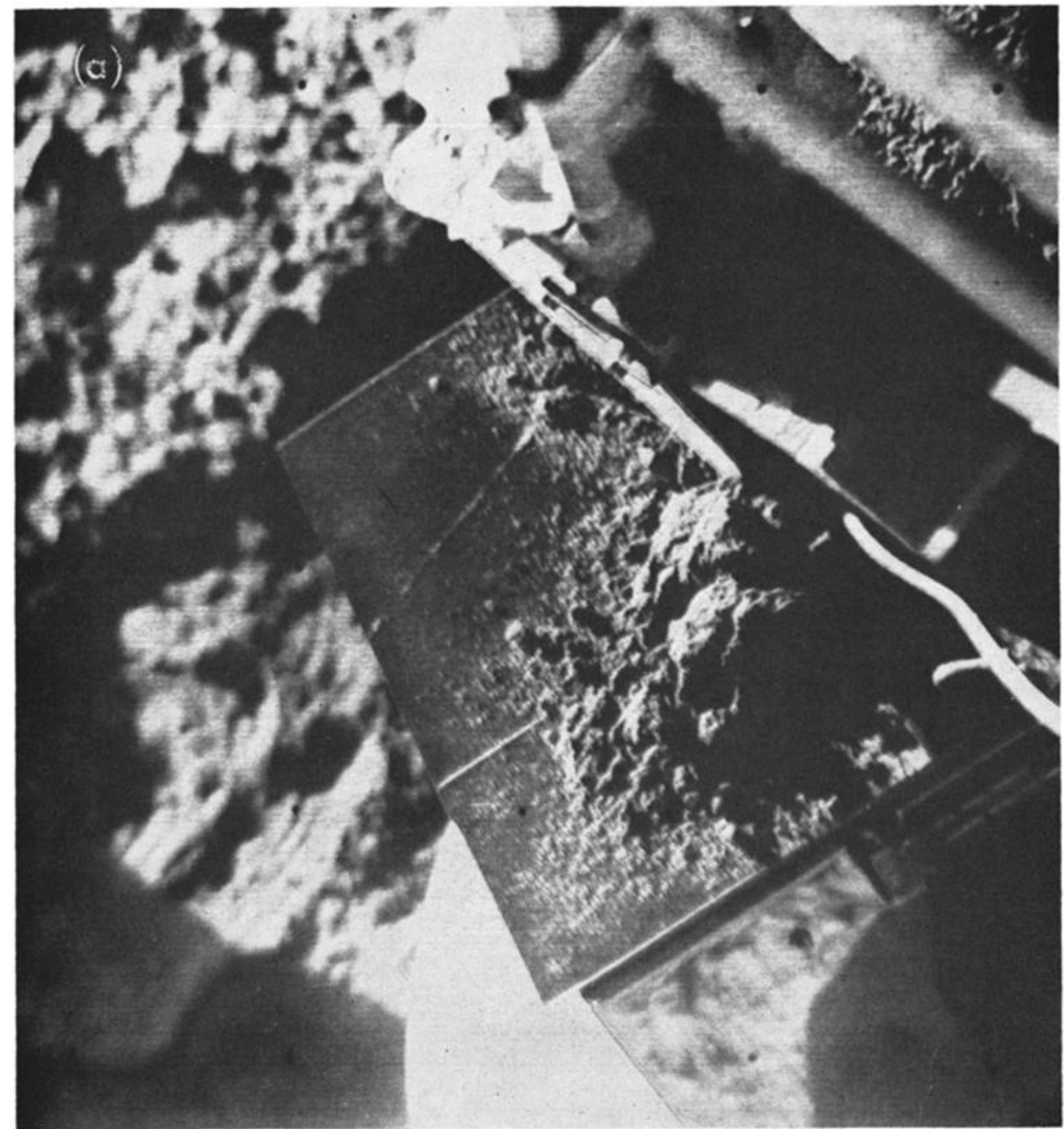

Fig. 29a. Lunar soil dropped on the sensor-head thermal mirror. 


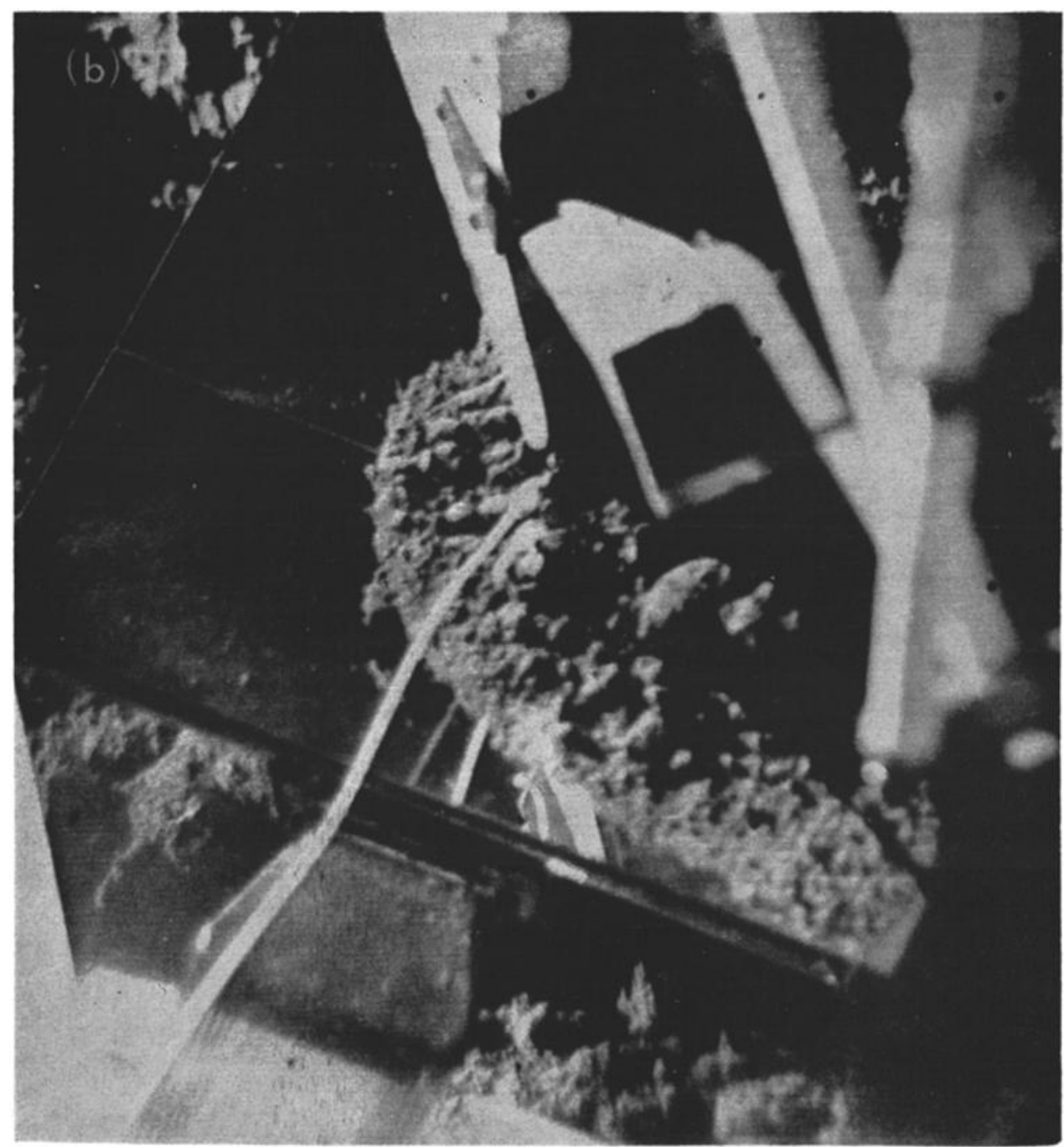

Fig. 29b. After redeployment of sensor head, showing soil movement.

To some slight extent, the soil around Tycho appears stronger or denser than the material in the maria. In general, the soil in the bearing tests and trenching operations in the Tycho area did not crack or split to the same extent as the soil in the Surveyor 3 mare area. During trenching operations, it appeared to yield or deform without breaking up into large individual chunks or fragments of aggregated material, as did the soil near Surveyor 3 [Scott and Roberson, 1967]. It is concluded, therefore, that the soil at the Surveyor 7 landing site, although cohesive, as evidenced by the smooth vertical walls of trench 2 and by other operations, did not exhibit the degree of cementing and brittle fracturing evidenced by the first few centimeters of the lunar surface in the mare area. The contrasting behavior of the soils on the moon may be related to the difference in ages of the Tycho blanket (younger) and mare materials (older), or to the slight chemical difference observed by means of the $\alpha$-scattering experiment.

To date, only a preliminary analysis has been made with command tape 907 and motor-current information. Bearing test 2 has been analyzed in this way by using motor currents in the form shown in Figures 5 and 6, together with the step-by-step motions of the surface- 
sampler scoop, given by the sequential pictures to give the force-versus-penetration curve of Figure 4. In Figure 4, it can be seen that some amount of penetration occurred at relatively low load. This initial part of the curve, which is commonly referred to in soil mechanics as 'seating,' is due to the initial wedge indentation of the sampler during a bearing test (see Figure 3 of Scott and Roberson [1967]), and it may also develop either from the irregular nature of the surface or from a layer of softer soil above underlying denser material. It will be seen from the curve that there is a tendency for the rate of penetration to increase at approximately $3.0 \times 10^{9}$ dynes of force. This value may be interpreted as a bearing capacity for this size of footing. After this point, however, the rate of penetration again decreases, and it seems likely that the increase is caused by an increasing strength or density of the material below a depth of a few centimeters. A more detailed interpretation of a number of bearing tests must be made before more general conclusions can be drawn.

Rock density. Based on measurements of the deflection of the surface sampler before and after dropping the rock, a preliminary estimate of the weight of rock A has been made. From the dimensions of the rock on the lunar surface, by comparison with the dimensions of the surface sampler, its volume has been estimated. The weight appears at this time to be accurate to within \pm 7 or $8 \%$; at best, the volume can be obtained within about $30 \%$. Since stereo pairs of pictures of the rock have been obtained, a more accurate calculation of its volume should be possible at a later date. By using the extremes of weight and volume obtained for the rock, it is estimated that its density lies within the range of 2.4 to 3.1 $\mathrm{g} / \mathrm{cm}^{\circ}$. Although such a determination is not of sufficient accuracy to be used in an evaluation of the rock type, if does indicate that the material of which the rock is composed is not substantially porous, since the density lies within the range of common terrestrial rocks.

If it can be assumed that this rock was characteristic of many of the other fragments around the Surveyor 7 landing site and that the soil tested by the surface sampler in the same area was derived by meteoritic bombardment of these rock fragments, it must be concluded that the individual particles composing the soil are, in themselves, not highly porous. This determination would appear to reinforce the conclusions obtained from the Surveyor 3 surfacesampler operations that, in fact, the strength and deformation characteristics of the lunar surface granular material can be explained by the presence of a material with a density comparable to that of common terrestrial soils, that is, in the range $1.5 \mathrm{~g} / \mathrm{cm}^{3}$ and greater. Bearing test data, such as shown in Figure 4, and other tests do appear to indicate the presence in some locations of a surface layer, possibly several millimeters thick, that is softer or more easily compressible than the underlying material. However, the material appears to gain in strength or density comparatively quickly as a function of depth in the first 1 or $2 \mathrm{~cm}$. The increase with depth will be evaluated to greater depths from the motor-current data obtained during various passes through trench 2 .

Observations. The lunar soil at the surveyor 7 landing site appears to be irregular in depth and relatively shallow, ranging in the surfacesampler area of operations from depths of less than $2.5 \mathrm{~cm}$ to a depth of at least more than $15 \mathrm{~cm}$. The soil is underlain by substantial rock fragments. It is estimated that, on the first earth day following lunar sunset, the drag tests performed in trench 1 exerted a force of at least 180 newtons on the subsurface fragment underlying that trench. An individual rock fragment resisting a lateral force of this order of magnitude on the moon would have a very substantial size. In none of the trenching operations in the lunar surface were other soil fragments brought up that were comparable in size to the pieces lying about on the surface. A distinct impression is gained from the surface-sampler work that the surface rocks lie on a relatively fine-grained granular material, and that this material does not contain rocks of comparable size to the fragments on the surface. However, the surface is underlain with substantially larger fragments. One normally expects in a granular material a gradation of fragments of all sizes distributed both horizontally and vertically through the material.

The rounded surface shape of rock $D$ and its angular subsurface shape appear to be indicative of some process of erosion, probably meteoritic bombardment at the surface. Al- 
though the undersides of some of the rocks excavated from the lunar surface were darker than the above-surface side of the rock, it appeared that this difference was due to a coating of fine-grained granular soil on the underside.

It has not been possible, to the present time, to calculate a value for the strength of the rock broken by the surface-sampler impact; however, the impact delivered was not the most violent that the surface sampler was capable of delivering, and the implication is that the rock was relatively weak, either intrinsically or as a result of an existing fracture in it.

As on Surveyor 3, little soil material appeared to adhere to the scoop early in the operations, but, as the lunar day proceeded, the soil showed a greater tendency to adherence. It was, however, comparatively easily dislodged, as, for example, during the process of picking up the sensor head to move it to its second position.

\section{SUMMARY}

The lunar surface at the Surveyor 7 landing site is covered with a fine-grained soil whose depth over rock or rock fragments varies from 1 or $2 \mathrm{~cm}$ to at least $15 \mathrm{~cm}$. Many rock fragments ranging in size up to $10 \mathrm{~cm}$ lie on the surface within the surface-sampler operations area.

The surface soil exhibits properties similar to the properties of the soil at the Surveyor 3 landing site. The behavior of the soil at a depth of several centimeters is therefore consistent with the behavior a material possessing a cohesion of the order of 0.35 to $0.7 \times 10^{4}$ dynes $/ \mathrm{cm}^{\circ}$, an angle of friction of $37^{\circ}$ to $39^{\circ}$, and a density of about $1.5 \mathrm{~g} / \mathrm{cm}^{3}$.

To a depth of several millimeters at the lunar surface, the soil appears less dense, softer, and more compressible than the underlying material.

The bearing capacity of the lunar soil to the 2.54-cm-wide area of the closed scoop of the surface sampler was about $2.1 \times 10^{5}$ dynes $/ \mathrm{cm}^{2}$, at a maximum penetration of about $3 \mathrm{~cm}$.

Qualitatively, the soil at the Surveyor 7 site was less brittle than at the Surveyor 3 site.
There was less general cracking, and tests and trenching operations provided smaller lumps or aggregates of lunar soil.

Rock material (or a rock) was encountered at two locations below the lunar surface, but it was too large or firmly embedded to be moved. No movable subsurface rock fragments were excavated.

The density of a single rock, which was picked up and weighed, was in the range 2.4 to $3.1 \mathrm{~g} / \mathrm{cm}^{3}$.

The excavation of one partially buried rock revealed that the subsurface portion was angular in contrast to the rounded visible portion.

One apparently intact rock was broken by a blow from the surface sampler.

The adhesion of lunar soil to the surfacesampler scoop appeared to increase with time on the lunar surface.

Little adhesion of lunar soil to the mirrored surface on top of the sensor head occurred in a 24-hour period.

Acknowledgments. The assistance and advice of M. C. Clary in the analysis of the performance of the mechanism and auxiliary, especially under critical temperature conditions during the mission, contributed materially to the success of the operation.

The work described herein was performed by the senior author under contract JPI-CIT 69811 with the Jet Propulsion Laboratory. The surface sampler was designed and built by the Hughes Aircraft Company, El Segundo, California.

\section{REFERENCES}

Rouze, E. R., M. C. Clary, D. H. LeCroissette, C. C. Porter, and J. W. Fortenberry, Surveyor surface sampler instrument, Jet. Propul. Lab. Tech. Rep. 32-1223, Pasadena, Calif., Feb. 1, 1968 .

Scott, R. F., and F. I. Roberson, Soil mechanics surface sampler: Lunar surface tests, results, and analyses, Surveyor 3 Mission Report, Part 2, Scientific Results, Jet Propul. Lab. Tech. Rep. 32-1177, 69-110, Pasadena, Calif., June 1, 1967. 